\title{
Controversias, hibridez y diseño urbano. Abrir el candado de la representación y multiplicar los posibles del espacio público'
}

\author{
Brais Estévez Villarino²
}

\begin{abstract}
RESUMEN
La proliferación de perspectivas relacionales en geografía humana está reanimando unos estudios urbanos que habían mostrado claros síntomas de agotamiento. Un conjunto de herramientas teóricas, instigadas desde la teoría del actor-red (ANT) y la teoría no representacional (NRT), han ayudado a abrir las condiciones de posibilidad de los objetos de estudio, ampliando la ecología política de la ciudad, y problematizando una concepción del espacio público entendido como un contenedor autoevidente y una realidad geométrica protagonizada por una dinámica social previsible. Además, esta crisis de representación epistemológica se ha visto acompañada por una crisis de representación política que ha erosionado la misma noción de delegación, cuestionando el rol de los expertos en los procesos de diseño urbano. Mediante el análisis de la controversia de la plaza de Lesseps de Barcelona, este artículo pretende pensar el espacio público de otra manera, rompiendo el cerco con el que la representación limitaba tanto su estudio como su diseño.
\end{abstract}

Palabras clave: cosmopolítica, espacio público, foros híbridos, teoría del actor-red, teoría no representacional.

\begin{abstract}
The proliferation of relational approaches in human geography is reanimating urban studies which have shown signs of exhaustion. Different theoretical tools incited from actor-network theory (ANT) and non-representational theory (NRT) are opening the conditions of possibility of the objects of study of our discipline, expanding their political ecologies and challenging the idea of public space conceived as a self-evident container. Moreover, this epistemological crisis coincides with a crisis of political representation that has eroded the notion of delegation, questioning the role of experts in the politics of urban design. In my paper, I study the urban controversy of the plaza de Lesseps in Barcelona, a contentious case study of urban planning which last refurbishment caused an unprecedented process of citizen participation that revealed a profound crisis of representation. In the light of the claims showed for this controversy, I want to rethink the public space, breaking the fence which the notion of representation restricted not only its study but also its design.
\end{abstract}

Key words: cosmopolitics, public space, hybrid forums, actor-network theory, non-representational theory. 
El día 11 de febrero de 2015, casi seis años después de la inauguración oficial de la remodelación de la plaza de Lesseps de Barcelona, una convocatoria vecinal realizada bajo la consigna "Combates por Lesseps" volvía a reunir en la emblemática iglesia de los Josepets de Gràcia ${ }^{3}$ a algunos de los actores más destacados de un litigio urbanístico que, en el cambio de milenio, contribuyó a desestabilizar la gobernabilidad urbanística de Barcelona y, sobre todo, puso de manifiesto el agotamiento de un modelo de transformación urbana que había dejado de funcionar como una fábrica de consenso. Gracias a la atenta y amable invitación que me cursó la entidad convocante -la asociación Amics de Lesseps-, mi nombre engrosaba la nómina de ponentes de una mesa redonda en la que, por primera vez, tenía la fortuna de compartir tribuna con algunas de aquellas personas expertas y activistas que protagonizaban muchas de las páginas de mi tesis doctoral (Estévez, 2014). Todas ellas -próximas, o más o menos encuadradas en las filas de la extinta plataforma vecinal Una altra plaça Lesseps és possible-, se habían significado públicamente en la lucha que condujo a la suspensión del proyecto que el Ayuntamiento de Barcelona había presentado a comienzos de 2002, y que la movilización vecinal obligó a retirar, negociar y consensuar mediante un proceso de participación inédito.

Ahora bien, ¿qué hacíamos allí reunidos los vecinos, activistas, arquitectos e investigadores presentes? ¿Por qué aquel mismo espacio que, otrora -poco más de una década atrás-, había servido para escenificar el consenso y cerrar la controversia en torno a la remodelación de la plaza, volvía a acoger un nuevo combate por Lesseps? ¿Qué había pasado para que de nuevo una de las dos grandes sensibilidades vecinales ${ }^{4}$ de la plaza decidiese convocar un acto público en el que la representatividad de los portavoces de Lesseps volvía a ser objeto de denuncia? O dicho de otra manera: ¿cómo era posible que después de un proceso tan largo y complejo, el derecho a hablar legítimamente en nombre de la plaza Lesseps volviese a estar en entredicho, y la disputa y la controversia se volviesen a cernir sobre este espacio?

\section{Descajanegrizar el espacio público, pensarlo de otra manera y liberarse de los constreñimientos de la representación}

En un excelente trabajo, Regan Koch y Alan Latham (2012) advertían de un serio problema que lastraba la capacidad heurística de las perspectivas convencionales en geografía urbana. A su juicio, los modos de hacer dominantes en la disciplina adolecían de una comprensión deficitaria de los objetos de estudio -fundamentalmente el espacio público- que, de no corregirse, corrían el riesgo de colocar a la geografía en una posición subalterna en el campo de los estudios de la ciudad. Como se desprendía de aquel texto, los trabajos de los geógrafos tropezaban una y otra vez con una serie de insuficiencias epistemológicas que, además de limitar su autoridad,

\footnotetext{
Popularmente conocida como Josepets, la iglesia de la Mare de Déu de Gràcia i de Sant Josep es, además del elemento fundacional del barrio de Gracia, un histórico lugar de encuentro y de enunciación de las cíclicas luchas vecinales de Lesseps.

La quiebra del consenso vecinal que ocasionó el último proceso de remodelación de Lesseps desencadenó la ruptura de la comisión vecinal Una altra plaça Lesseps és possible dando lugar a dos asociaciones de vecinos enfrentadas: Amics de Lesseps -en la que permanecian los principales líderes de la comisión, alineada con la ratificación de la formalización de la plaza pero con escaso dinamismo desde la finalización de las obras- y la Associació de Veïns i Comerciants de la Plaça Lesseps (AVC Lesseps)-que asumió casi en exclusiva el rol de portavoz vecinal de Lesseps tras la inauguración de la plaza, y aglutina vecinas vecinos y comerciantes de Lesseps críticos con la formalización y el diseño del espacio.
} 
habían vuelto las investigaciones sobre el espacio público sumamente previsibles, repetitivas y redundantes. En efecto, debido al anclaje del tropo espacio público en una concepción sustancial -heredera de una tradición canónica de los estudios urbanos que aludía a ágoras, accesibilidad universal, esferas de deliberación intersubjetiva, etc.-, las perspectivas mayoritarias restringían el foco investigador al estudio de una serie de fenómenos predecibles que, de una u otra manera, remitían a una suerte de esencia, a saber: una representación previa y un a priori sustancial -inscrito en alguna de las nociones propias de aquel canon-, con el que se establecía una especie de dependencia ontológica. De alguna manera, el espacio público era tratado como un fetiche, como si fuese un epifenómeno de otro tipo de dinámica o proceso realmente importante, que la geografía tenía sobradamente codificado en su repertorio conceptual.

Ahora bien, el texto con el que Koch y Latham (2012) alertaban del estancamiento investigador a que habían conducido las maneras de hacer dominantes en geografía urbana no operaba de manera aislada. Al contrario, revelaba una clara filiación epistemológica que lo adscribía a una serie de trabajos, corrientes y propuestas emergentes que, con especial intensidad desde finales de la década de 1990, habían volteado las ciencias sociales (Latour, 2007a; Domènech \& Tirado, 1998), llegando a hacer implosionar diferentes áreas de la geografía humana (Thrift, 1996).

En efecto, la irrupción de las alternativas epistemológicas, relacionales, constructivistas radicales y antiesencialistas, que -primero, bajo la etiqueta de teoría del actor-red (ANT ${ }^{5}$ ) y, posteriormente, también de la mano de la teoría no representacional (NRT)- habían acudido al rescate de unas ciencias sociales recluidas en unos marcos exhaustos y asaltados por una fuerte crisis de representación que problematizaba muchas de sus asunciones, certezas y prejuicios, desencadenaría el proceso de cuestionamiento, cambio de óptica y replanteamiento analítico y conceptual que Koch y Latham señalaban en su trabajo.

\section{La teoría del actor-red (ANT)}

No se puede entender la aparición y el auge de este nuevo programa teórico sin reparar antes en el gran desafío epistemológico que la ANT planteó al conjunto de las ciencias sociales, a raíz del impacto que sus nuevas perspectivas de investigación -desarrolladas desde finales de los años 1970- causaron en diferentes asunciones del pensamiento moderno. Gestada en el campo de los Estudios Sociales de la Ciencia y la Tecnología (STS), algunos de los pioneros de la teoría del actor-red edificaron esta perspectiva mediante una serie de trabajos (Callon, 1995; Latour, 1992; Latour \& Woolgar, 1979; Law, 1987) que desplegaban dos estrategias encaminadas al análisis de la ciencia en acción: por una parte, la descripción empírica de las prácticas científicas en los laboratorios -allá donde se producían los hechos y el conocimiento-, y, por otra parte, el estudio de controversias científicas y tecnológicas -a saber, el análisis de procesos de innovación científico-técnica aquejados de una gran incerteza y cuyo éxito no estaba ni mucho menos asegurado. Ahora bien, tal y como sostenían Domènech y Tirado (1998), la ANT iba más allá de una mera propuesta metodológica para estudiar la ciencia y la tecnología; y, de manera inopinada, los conceptos, postulados y asunciones que esta perspectiva generó en sus estudios de la "ciencia

A lo largo de este trabajo se utilizan las siglas ANT, NRT y STS. La primera se corresponde con la abreviatura de Actor-Network Theory -en castellano, Teoría del Actor-Red-, la segunda hace referencia a Non-Representational Theory -Teoría no representacional-, mientras que la tercera identifica el área de los Science and Technology Studies -Estudios Sociales de la Ciencia y la Tecnología. A falta de acrónimos convicentes en castellano, he optado por mantener todas estas abreviaturas en inglés. 
mientras se hacía" (Latour \& Woolgar, 1979), sirvieron para perpetrar una innovadora reflexión sobre la producción del orden y el vínculo social que acabaría resquebrajando algunos de los pilares que sostenían el pensamiento moderno.

Lo que la ANT puso de manifiesto mientras estudiaba la ciencia fue la convicción de que esta no podía ser abordada adecuadamente sin abandonar antes un marco binario que operaba como punto de partida del pensamiento y forzaba a la separación acrítica de contextos. En efecto, aceptando el rol estructurante de los dualismos más característicos del pensamiento moderno -sujeto/objeto, naturaleza/sociedad, sensible/inteligible, local/global, humano/no humano, cuerpo/ mente, agencia/estructura-, los primeros estudios sociales de la ciencia y la tecnología-aquellos inspirados por el construccionismo social- abrazaban una prioridad ontológica de lo social que reducía casi cualquier tipo de fenómeno a factores sociales. Ahora bien, como afirmaban autores como Latour (2007a), Callon (1995) o Law y Mol (1993-1994), estos planteamientos nunca se cuestionaban el carácter construido de lo social ${ }^{6}$ y, al contrario, daban por supuesto que social era una sustancia o un dominio específico de la realidad -diferente a lo natural o lo técnico-, que actuaba como factor explicativo y que en ningún caso cabría analizar (Latour, 2000, 2008). Es decir, las perspectivas herederas del construccionismo social no solo caían en una explicación social de la ciencia que descuidaba fenómenos imprescindibles para su comprensión -como lo no humano, la naturaleza y lo tecnológico- sino que la misma concepción hegemónica de lo social que utilizaban -un contexto o un marco exclusivamente humano-, operaba como una trituradora esencialista en el seno de cuyas dinámicas -fuertemente reificadas- había que acomodar y mutilar los objetos de estudio para su explicación. Precisamente, uno de los principales logros de la ANT en su primera etapa residió en su ingenio para iluminar una deficiencia básica, la imposibilidad de estudiar las prácticas científicas en términos exclusivamente sociales; entre otras cosas, porque, como señalarían Law y Mol (1993-1994), lo social no era puramente social.

Efectivamente, la ANT venía a decir lo siguiente: a la luz de sus estudios sobre la ciencia, tanto los laboratorios como las controversias tecnocientíficas afloraban como entornos tremendamente complejos, cuya dinámica, en términos de indagación y conocimiento, resultaba inasible si no se tenía en cuenta la participación de una multitud de actores heterogéneos (entidades de todo tipo, relaciones, materialidades, artefactos, etc.) que desbordaban los estrechos límites de lo social. Es decir, en el estudio de la ciencia ningún fenómeno venía dado por la sociedad ni por la naturaleza, sino que había sido formalizado y adscrito a una de estas dos esferas después de un ingente trabajo de investigación y negociación.

Para salir de semejante atolladero, la ANT propuso una serie de principios, asunciones y procedimientos que, a pesar de haberse gestado en el marco de los STS, en seguida irrumpieron en las ciencias sociales. Aquejadas estas de una crisis de representación epistemológica que señalaba la merma de su capacidad analítica y una dificultad cada vez más problemática para dar cuenta de lo social en el mundo contemporáneo, investigadores de diversas disciplinas como la antropología, la sociología, la filosofía, la psicología social o la geografía (Law \& Hassard, 1999) aceptaron el reto de la ANT: desafiaron la episteme de la modernidad desde sus respectivas tradiciones,

\footnotetext{
En palabras de Latour, la asimetría cometida por la sociología del conocimiento radicaba en desplazar el peso de las explicaciones al polo de la sociedad, resultando constructivistas para la naturaleza pero realistas para la sociedad: "Pero la sociedad, no es menos construida que la naturaleza. (...). Naturaleza y sociedad no ofrecen sólidos ganchos a los que podamos aferrar nuestras interpretaciones, sino aquello que, por el contrario, conviene explicar" (Latour, 2007a: 142-143).
} 
adaptaron el repertorio conceptual y el estilo investigador de la teoría del actor-red, y empujaron sus áreas de estudio hacia terra incognita.

Precisamente, la articulación de una sensibilidad diferente y la puesta en marcha de un estilo de investigación agnóstico y desencializante (Callon, 1995; López, 2012) que rompiese con la tradicional dependencia de un largo conjunto de apriorismos ontológicos, verdaderas esencias y principios sustanciales -que limitaban y disciplinaban los objetos de estudio en lugar de facilitar su explicación-, forjaría el espíritu y los principios más característicos de la ANT.

El primero de ellos, el principio de agnosticismo ontológico (Callon, 1995; Latour, 1992), niega que los objetos de estudio sean realidades autoevidentes o que posean una esencia sustancial e inmutable que la ciencia debiera revelar impulsada por el afán purificador del pensamiento moderno. En efecto, el principio de agnosticismo previene contra cualquier distinción esencial, es decir, en lugar de partir de la premisa de un apriori sustancial que ataría la realidad a una representación previa, la ANT formula una ontología relacional del mundo que entiende que este, lejos de componerse de entidades autoevidentes, está hecho de relaciones entre entidades heterogéneas, cambiantes, tremendamente prolíficas y ajenas de entrada a la dualización moderna. Es así como la sensibilidad agnóstica desactiva la dependencia ontológica señalada anteriormente y, desde una perspectiva ANT, los objetos de estudio ya no se verán sometidos a las constricciones que impondría su encaje en un canon previo y en una dinámica social preconcebida.

Otro de los principios metodológicos que la ANT generó en su estudio de la actividad científica es el de simetría generalizada (Callon, 1995; Domènech y Tirado, 1998; Latour, 2007a). Posiblemente su principio más característico, la exigencia de simetría y, por consiguiente, la demolición de toda forma de dualismo en el estudio del mundo, emergió como respuesta a las fuertes limitaciones identificadas en el análisis empírico de las prácticas científicas. Abrumados por la gran diversidad de actores, recursos y elementos heterogéneos que participaban de la producción de los hechos científicos, los fundadores de la ANT decidieron poner fin a la dicotomización como a priori del conocimiento, asumiendo que las distinciones binarias, en lugar de punto de partida de cualquier análisis, debían ser entendidas como efectos o consecuencias de la dinámica de un sinfín de relaciones heterogéneas ${ }^{7}$ que no se podían restringir a lo social. En efecto, el principio de simetría insta a sumergirse en las prácticas, y a estudiarlas de manera simétrica, eximiéndolas de los constreñimientos binarios que obligaban a escoger entre polos -humanos y no humanos, social y natural, causas y consecuencias o verdadero y falso. De esta manera, liberando a la investigación de una traba muy común en la actividad científica con ascendencia en el construccionismo social -como era la simplificación de una multiplicidad heterogénea en la retórica pacificada de lo social-, los objetos de estudio dejan de remitir a entidades preexistentes, puras o autoevidentes - propias de un marco binario-, y pasan a conceptualizarse como efectos relacionales, inciertos, complejos, híbridos y múltiples, sin una identidad fijada de antemano que permitiese deducir sus dinámicas.

Como explicaban Law (1987) y Callon (1998), los estudios empíricos de la actividad científica y tecnológica ponían de manifiesto la existencia de procesos de ingeniería heterogénea que, además de señalar que un hecho o una innovación científica eran el efecto de la asociacion, alineación y coordinación en una misma red de un conjunto de elementos sumamente dispares y heterogéneos -artefactos, subvenciones, intereses, publicaciones, naturalezas, etc.-; también evidenciaban que la preeminencia explicativa que se le había otorgado a lo social en los STS debía ser abandonada, exhortando a los analistas a utilizar un mismo estilo de explicación en sus descripciones de la realidad humana y no humana 
Precisamente, la conciencia de que los objetos de estudio no tenían una esencia prefijada y que, antes que realidades autoevidentes, eran emergencias, productos y efectos de un conjunto de relaciones heterogéneas, condujo a la ANT a realizar un giro semiótico (Law, 1999, 2008) y asumir la "premisa de la heterogeneidad" (Domènech y Tirado, 1998). Como se encargan de subrayar estos mismos autores, con este postulado la teoría del actor-red manifiesta que la heterogeneidad de las partes es previa a la unidad del todo, ya que, desde una mirada semiótica, toda entidad -por muy singular o discreta que pueda parecer- no deja de ser el mero efecto de una red de relaciones que establece y mantiene con otros actores.

Por este motivo, los procedimientos de trabajo de la ANT, al reconocer el carácter híbrido, contingente y cambiante del mundo, destacan siempre por abordar las cosas in medias res (Latour, 2008: 47); es decir, priorizan el cómo antes que el qué y, en lugar de abalanzarse sin más sobre entidades aparentemente estables y coherentes, se esfuerzan por centrar su atención en entramados de fenómenos y relaciones heterogéneas y en curso.

Ahora bien, la singladura teórica previa resultaría huera para este trabajo de no ser por las profundas consecuencias que las propuestas y los principios reseñados anteriormente entrañaron para las ciencias sociales. Más allá de un replanteamiento genérico de categorías fundamentales como naturaleza y sociedad -que pasan de considerarse ejes articuladores a efectos relacionales-, el golpe que la ANT atestó a las ciencias sociales radicó nada menos que en la desontologización y redefinición de la noción de social. En efecto, si lo social era un logro -un efecto relacional y una construcción heterogénea-, la asunción de su carácter construido echaría por tierra el recurso a lo social como factor explicativo, al menos según su significado dominante. Como afirmaba Latour (2000), dar una explicación social de algún tipo de fenómeno, conforme el modus operandi convencional de las ciencias sociales, implicaba destruir los objetos de estudio al verse estos reducidos a una dinámica social preconcebida que -y aquí el error con consecuencias más graves para el espacio público- impedía otras articulaciones y disposiciones de las cosas no prescritas en su repertorio. Teniendo en cuenta la lección extraída del estudio de la actividad científica -de nada valía limitarse a una explicación social-, la superación de este problema pasaba por redefinir la noción de social, asumir que en lugar de explanans era explanandum -no explica nada sino que debe ser explicado- $y$, por lo tanto, rehabilitar la capacidad originaria de social para rastrear conexiones (Latour, 2008: 19) y hacer proliferar explicaciones. En lugar de una sustancia, un marco o un dominio específico de la realidad diferente a lo natural o técnico, para Latour, social se concebía como un proceso de asociación de entidades heterogéneas y no sociales en sí mismas -objetos, tecnologías, naturalezas, textos, actores humanos, afectos- que no distinguía de entrada entre humanos y no humanos. Así pues, rehuyendo una decisión previa que condujese a dar por supuestas las características de lo social -circunscrita a algún tipo de afer intersubjetivo y exclusivamente humano-, la ANT elaboró una conceptualización alternativa según la que las asociaciones establecidas entre entitades heterogéneas serían lo que daría lugar a los diferentes relieves de lo social:

"Desde el punto de vista alternativo, lo "social" no es un pegamento que pueda arreglar todo, incluyendo lo que otros tipos de pegamento no pueden arreglar; es lo que está pegado por muchos otros tipos de conectores. En este significado del adjetivo, lo social no designa algo entre otras cosas, como una oveja negra entre ovejas blancas, sino un tipo de relación entre cosas que no son sociales en sí mismas (...) Ésta es la razón por la que voy a definir lo social, no como un dominio especial o un tipo de cosa particular, sino como un movimiento muy peculiar de reasociación y reensamblado". (Latour, 2008: 18-19-21). 
Es ahora cuando, más allá de un ejercicio de virtuosismo epistemológico, puede cobrar más sentido la potencia política del estilo agnosticista que propone la ANT. Si tal y como sostiene Daniel López (2012), la ANT es ante todo una máquina de proliferación de articulaciones y de otras maneras de explicar, ¿no quiere decir esto que, a lo mejor, las cosas pueden ser de otra manera a cómo las habíamos visto y explicado? ¿No está en condiciones la ANT, desde su firme disposición a atender a las disposiciones múltiples de la sociedad y el espacio, de multiplicar los posibles de nuestros objetos de estudio más allá de los estrechos límites de lo conocido y lo dado? ¿Pueden hallarse entre sus orientaciones respuestas a la crisis de representación epistemológica que azota a la geografía urbana que sean útiles para poner fin a la predictibilidad y la propagación de redundancias de los estudios sobre el espacio público?

\section{Abrir el candado de la representación. La teoría no representacional (NRT) como devenir minoritario de la geografía urbana}

Casi como una secuela del giro desencadenado por la ANT en la sociología del conocimiento, la geografía se sumó a aquella suerte de tormenta epistemológica -seguidamente desatada sobre las ciencias sociales- con un movimiento propio: la teoría no representacional (NRT). Tras haber detectado en su seno síntomas de un cierto apoltronamiento intelectual cuyo rasgo más significativo, la estatización del espacio -su principal objeto de estudio-, estaría dando lugar a unas "geografías muertas" (Thrift y Dewsbury, 2000), diferentes autores, más o menos inscritos en los debates propiciados por la ANT, se entregaron a la tarea de reanimar la geografía humana:

"Creo que muchos de los protocolos de las actuales ciencias sociales y humanidades son, no solo equivocados, sino, lo que es peor, opresivos. (...) Reconozco que la geografía me frustra con frecuencia. En gran medida, parece seguir la lógica del cadáver, estar interesada en lo roto, lo estático y lo ya sucedido. Por ello, a lo largo de los últimos 20 años, he intentado desarrollar un enfoque que propone otras maneras de relacionarse con un mundo más animado. A este enfoque le llamo 'teoría no representacional'" (Thrift, 2004: 81-83, traducción propia).

Un objetivo acuciante si como era de suponer no se quería continuar ensanchando la peligrosa brecha abierta entre las dinámicas del mundo contemporáneo -híbridas, múltiples, heterogéneas, radicalmente relacionales- y los marcos epistemológicos dominantes en la geografía urbana y cultural de la década de 1990 -anclados en los marcos interpretativos, las políticas de la representación, la búsqueda de significados y la producción de nuevos significantes urbanos.

Acuñada y desarrollada por Nigel Thrift $(1996,1997,2004,2007)$ desde la segunda mitad de los años 90, y rápidamente adoptada por otros geógrafos británicos como Loretta Lees (2001), Alan Latham (2003), Sarah Whatmore (2006), Hayden Lorimer (2005, 2007, 2008) o Rachel Colls (2012), la NRT constituyó la respuesta más innovadora de la geografía a aquellas limitaciones impuestas por los modos de hacer imperantes en la geografía urbana y cultural de los años 80 y 90 -cuando estas se encontraban tomadas por el construccionismo social y las geografías postmodernas, pero también por una geografía radical incapaz de ir más allá de la gramática de la economía política y de una distribución de los posibles dada de antemano.

Como señalaban los propios Thrift (1996), Lees (2001) o Latham \& Conradson (2003), la geografía cultural finisecular se había convertido en una disciplina obsesionada con las representa- 
ciones, acotando su agenda investigadora a la interpretación de una dimensión simbólica, textual y discursiva de la realidad que descuidaba una multitud de fenómenos -de naturaleza práctica, encarnada, afectiva y emergente- que, una y otra vez, desbordaban un modelo de conocimiento que confiaba en exceso en la razón como motor exclusivo del saber. En efecto, concibiendo lo urbano como un texto cifrado de antemano que debía ser leído e interpretado -un lugar para explorar discursos, símbolos y producir metáforas ingeniosas (oficialistas o alternativas) que permitían otorgar significados a la ciudad ${ }^{8}$, los fenómenos analizados se veían sometidos a una suerte de guion previo que, desde la escasa sensibilidad hacia la inmanencia de las prácticas que realmente podrían dar lugar a aquellas representaciones, desestimaba y supeditaba muchas de las agencias que componían la ciudad en favor de sus necesidades discursivas. Es decir, desde el punto de vista analítico, la prioridad ontológica para el construccionismo social residía en los significados, los órdenes simbólicos y las relaciones de poder; de manera que las prácticas, los cuerpos, las interacciones y las relaciones se entendían como simples epifenómenos y expresiones más o menos ilustrativas de lo realmente importante: las representaciones sociales y espaciales.

Precisamente, para socavar esta preponderancia textual y discursiva -que operaba de manera análoga a la prioridad de lo social que la ANT problematizó en los STS-, la NRT decidió situar el ethos investigador de la geografía humana en una dimensión práctica del mundo y del conocimiento que ponía en jaque los modelos contemplativos legados por la metafísica cartesiana:

"la teoría no representacional proporciona una crítica de la separación entre sujeto conocedor y mundo tan característica de los modelos pos-Cartesianos, tanto en su versión idealista (la creencia de que el acceso al mundo tiene lugar por medio de formas que existen en nuestras mentes), como realista (la creencia en un mundo objetivo que debería ser alineado con nuestras percepciones); esto es, formas de pensar que han persistido en los habituales modos representacionales del pensamiento" (Cadman, 2009: 457-458, traducción propia).

De alguna manera, después de haberse hecho la pregunta de qué pasaría si la geografía se tomase realmente en serio las prácticas, la NRT puso en marcha un programa investigador caracterizado por la voluntad de abrir el candado de la representación. Al reconocer que la representación funcionaba como una "imagen dogmática del pensamiento" (Deleuze, 2002: 204-205) que mantenía en pie aquellos dualismos que dificultaban pensar de otro modo -imposibilitando ver y sentir fenómenos inexistentes dentro de los marcos modernos-; y, como consecuencia de lo anterior, aquel candado aseguraba una relación epistemológica de correspondencia entre los fenómenos analizados y sus representaciones científicas -simplificando un mundo activo y múltiple en la retórica homogeneizadora y preconcebida de las categorías convencionales-; la NRT irrumpía, y aquí su valor político ${ }^{9}$, como alternativa a la crisis de representación política y epistemológica en curso.

\footnotetext{
Entre el repertorio más idiosincrásico de los enfoques representacionales se encuentran muchos de los debates propiciados por el llamado Modelo Barcelona, obras célebres de la geografía urbana española como la Urbanalización de Francesc Muñoz (2008), los trabajos de los autores más populares de la denominada Escuela de Los Ángeles como Mike Davis o Edward Soja -véase Lees (2003)-, o una infinidad de estudios sobre la gentrificación.

9 Ante las críticas de autores de gatillo fácil que achacaban un carácter naif, apolítico -e insensible a la política de las identidades- en la teoría no representacional, Thrift en seguida subrayó su marcado compromiso político, formulándolo, eso sí, más allá de las alternativas preconcebidas: "[la NRT] quiere que las cosas sean más políticas, mucho más políticas, pero, sobre todo, pretende ampliar el actual abanico de alternativas y sus correspondientes formas de disenso. Lo que el enfoque performativo pone de manifiesto es el sinfín de registros en que
} 
Sin duda, al proponer un pensamiento orientado a las prácticas, las relaciones y la afectividad $^{10}$, además de problematizarse la ruptura moderna que disociaba conocimiento y mundo -o sujeto conocedor y objeto conocido-, la NRT asumía que el conocimiento se generaba en el seno de los devenires y la inmanencia, antes que en atalayas aisladas o domicilios trascendentes (Haber, 2011) que acostumbraban a investir a las personas investigadoras de un rol de espectadoras y narradoras privilegiadas. Para la NRT, el mundo/espacio no está ahí afuera, escindido del investigador, esperando impasible, estático, inerte y subsidiario de las formas de conocimiento del analista; al contrario, la teoría no representacional se caracteriza por rechazar aquellas geografías muertas que permitían dar cuenta de los fenómenos recurriendo a fuerzas extrínsecas de causalidad -relaciones de poder, órdenes simbólicos, significaciones dominantes, etc.- que siempre encontraban una imagen previa, un fundamento anterior, una representación, una trascendencia o la verdad epistemológica de turno a la que agarrarse para acomodar y normalizar la multiplicidad y la alteridad espacial. Atreverse a pensar de otra manera y, por lo tanto, perpetrar un devenir minoritario"1 (Deleuze y Guattari, 1978) en la geografía urbana que permitiese contar con algo parecido a una noción de espacio público menor, implicaba cuestionar ideas y maneras de hacer fuertemente afincadas en la geografía urbana y cultural. Sin ir más lejos, la noción de social utilizada mayoritariamente en la geografía, la cual comportaba un sometimiento de los objetos de estudio a la imagen dogmática que proyectaba aquella idea convencional de social.

Para salir de la lógica que había conducido a la geografía a aquella crisis de autoridad señalada más arriba, resultaba imprescindible abandonar los modos representacionales, desterritorializar la lengua dominante -su aparato teórico hegemónico- y poner fin a aquella dinámica investigadora que, ensimismada en la búsqueda de correspondencias entre los fenómenos y sus representaciones epistemológicas (modernas y sociales), se había ido agotando hasta ver seriamente comprometida la eficacia de sus recursos epistémicos.

Como sostenía Thrift (2004), su voluntad con la NRT era la de encontrar un estilo de investigación que le permitiera expresar otras posibilidades de pensamiento a la geografía ${ }^{2}$; a saber, explorar e innovar antes que cartografiar lo dado $y$, sobre todo, multiplicar los posibles políticos

operan lo político y la acción política, más allá de nociones encorsetadas y restrictivas. Para aquellos que quieren la política de siempre, en la que se conocen las respuestas antes de que se respondan las preguntas, este enfoque, ciertamente, tiene poco que ofrecerles" (Thrift, 2003: 2021-2022, traducción propia).

10 La definición spinoziana de afecto, recuperada por Deleuze para el pensamiento contemporáneo (véase Deleuze, 2008), y posteriormente actualizada por Brian Massumi (2002), entiende la afectividad como una cualidad de la vida ajena a la cognición; una suerte de intensidad prepersonal cuya dinámica puede hacer aumentar las capacidades de un cuerpo para actuar. Según Spinoza (véase Deleuze, 2008: 226), este devenir intangible, potencia y diferencia de intensidad, actúa de dos maneras: a) como affectio, la afección de un cuerpo sobre otro, y b) como affectus, aquellas claves emocionales que una afección deja en la mente y el cuerpo de las personas y, por lo tanto, en su capacidad para actuar y reconectarse con el mundo

En palabras de Isaac Marrero, los proyectos minoritarios en ciencias sociales "proponen una reimaginación de sus respectivas disciplinas a partir de la ontología de la multiplicidad" (Marrero, 2012: 332). A su vez, Michael Buser considera que los estudios de la ciudad y el planeamiento urbanístico pueden beneficiarse de lógicas menores si se entienden como: "lineas de fuga alejadas de las identidades espaciales convencionales y de las categorizaciones estáticas, que avanzan hacia modos exploratorios y no convencionales de experimentación del mundo" (Buser, 2014: 231, traducción propia)

12 Entre otras cosas, una de las innovaciones heurísticas aportadas por la NRT fue su interés por lo preindividual, lo precognitivo, lo no intencional y presubjetivo -elementos que habían permanecido excluidos de la caja de herramientas consideradas útiles para el conocimiento-. Apostando por indagar en una dimensión afectiva del mundo -anterior a la cognición, la subjetividad y la comprensión racional- en la que los fenómenos, por así decirlo, antes que iluminados por la conciencia de sujetos autónomos, quemaban y eran experimentados -y manipulados- como diferencias de intensidad, la geografía dio un paso más en su desborde representacional que la llevó desde lo textual y lo simbólico hacia el compromiso ético con las materialidades, las disposiciones corporales, las emociones y la performatividad del mundo. 
y conceptuales del mundo, abriendo las investigaciones sobre la ciudad a una multitud de cuestiones que no se encontraran marcadas de antemano por un fundamento previo prescrito en las categorías modernas:

“La teoría no representacional es, por así decirlo, una máquina para la multiplicación de las cosas y, por ende, para la invención de nuevas relaciones entre el pensamiento y la vida. Mi intención es desestabilizar una política mesiánica que todavía opaca buena parte del pensamiento en ciencias sociales -establece un paradigma, busca aliados, aplica las ideas, produce trascendencia-, en favor de algo que puede que sea mucho más incierto, pero también mucho más productivo" (Thrift, 2004: 82; cursiva del autor; traducción propia).

Esta invitación a pensar e investigar de otra manera mediante las lógicas menores que proponía la NRT -y sin duda también la ANT- permite realizar una operación esencial para este artículo: la descajanegrización del espacio público. Además de un neologismo enrevesado, la metáfora de la (des)cajanegrización es uno de los recursos conceptuales más habituales de la literatura de los STS y, como advertía Latour (1992, 2001), señala una paradoja tecnocientífica significativa. A medida que un hecho científico o un artefacto técnico se estabilizaba, funcionaba correctamente, y su uso y/o aceptación se difundían, buena parte de los procesos y relaciones heterogéneas que posibilitaban su éxito eran objeto de un proceso de simplificación que ocultaba su complejidad interna "en una caja negra". En su etapa de estudio de la ciencia, harto de las insuficiencias heurísticas derivadas del escamoteo analítico de aquellos procesos opacos, Latour se propuso descajanegrizar la ciencia. Aquella maniobra facilitaba el rastreo y análisis de una multitud de cuestiones -recursos, discursos, materialidades y prácticas- que, a pesar de formar parte de la red que producía los hechos científicos, solían permanecer ocultas en sus relatos, sepultadas bajo la facticidad incuestionable de los hechos. En otra muestra de su interés por el cómo antes que por el qué, Latour decidió abrir la caja negra de unos fenómenos considerados como algo dado y aproblemático, y se comprometió con la indagación de aquella complejidad y heterogeneidad inherente al éxito de todo fenómeno.

Pues bien, como un efecto más de la crisis de representación que de un tiempo a esta parte problematiza certezas y acuerdos forjados por la modernidad -asumidos además como pilares de las democracias representativas (véase Callon et al., 2009)-, la caja negra del espacio público parece estar sucumbiendo ante la proliferación de las embestidas democratizadoras que, ajenas a las directrices de unos consensos desbordados, litigan sobre una multitud de elementos que otrora habrían permanecido cajanegrizados -exentos de escrutinio ciudadano. En efecto, la crisis de representación política y epistemológica en curso (Latour, 2004a; Graña, 2005) ha puesto de manifiesto un volteo del mundo que señala una evidencia: su funcionamiento dista mucho de ser eficiente y aproblemático. Es en este contexto de asedio a la representación -protagonizado por todo tipo de fuerzas que exigen abrir su candado para acceder y disputar sus contenidos opacosque la abollada caja negra del espacio público parece haber implosionado. Además, debido al empeño de las nuevas demandas, la descajanegrización del espacio público estaría liberando a este objeto de estudio de las servidumbres de una pretendida autoevidencia que limitaba su ecología política ${ }^{13}$ y, sobre todo, sustraía muchas de sus mediaciones a la deliberación y el control popular. El concepto de ecología política urbana (EPU), desarrollado fundamentalmente por geógrafos radicados en la Universidad de Manchester
como Noel Castree, Maria Kaika y Eric Swyngedouw, no se ha limitado a introducir la crítica y los modos de la ecología política en lo urbano. 
Siguiendo las orientaciones de la ANT y la NRT, de poco vale dar nada por descontado o considerar un objeto de estudio como algo autoevidente. Si los hechos científicos, a poco que se les conceda una segunda mirada, devienen en fenómenos mucho más complejos que la mera facticidad -evidencias incuestionables legitimadas por su propio estatus científico-, lo mismo sucede con el resto de entidades que pueblan el mundo. En efecto, ante una aproximación no representacional-agnóstica, cuidadosa e interesada (López, 2012: 160)- los objetos de estudio se vuelven recalcitrantes (Latour, 2000, 2008; Stengers, 2010), pueden objetar e impugnar lo que se dice sobre ellos, exhiben su multiplicidad, exhortan al analista a pensar de otra manera -más y mejor-, llegando incluso a forzarlo a lidiar con objeciones que cuestionan la validez universal de la categorización moderna del mundo.

Si las perspectivas representacionales limitaban las posibilidades conceptuales y políticas del mundo a un escaso repertorio de alternativas preconcebidas y autorizadas por el pensamiento moderno, las no representacionales se caracterizan por su compromiso con la multiplicidad y la inmanencia, la indeterminación ontológica de los objetos, la heterogeneidad y la ambivalencia, la innovación, la diferencia -en sí misma, como instancia positiva, productiva y sin una imagen previa-, etc.; y, especialmente, muestran una inclinación evidente por las "cuestiones de interés" en lugar de por las "cuestiones de hecho"14. Como sostenía Thrift (2004), su deseo con la NRT no era otro que encontrar un estilo de investigación de cariz performativo (en el que nada estuviera prefijado y cuyos objetos de estudio resultaran indisociables de las herramientas analíticas y conceptuales empleadas para conocerlos y hacerlos existir) que, a su vez, permitiera conceptualizar el mundo como un objeto de estudio más poroso y abierto a más cuestiones; dándole una oportunidad política y epistemológica a aquellos fenómenos que resultaban invisibles para el régimen dominante -bien porque no se amoldaban a ninguna esencia, o bien porque excedían los límites de lo que se consideraba objeto legítimo de conocimiento según los marcos epistémicos hegemónicos. Tanto la ANT como la NRT destacan por multiplicar los actores y por introducir otras fuerzas, cuerpos, voces y saberes en sus investigaciones, en una estrategia encaminada a hacer visibles cuestiones de interés -otras formas de realidad y de vida-ignoradas por la representación y silenciadas, invisibilizadas o reprimidas por las cuestiones de hecho.

En este sentido, si como afirma Daniel López, la ANT consiste en "hacer proliferar las maneras de explicar algo y por tanto multiplicar nuestros objetos de estudio" (López, 2012: 160) y, por decirlo con palabras de Nigel Thrift, el carácter político de la NRT "no reside en la formulación de un conjunto de demandas cerradas sino en el reconocimiento y la asunción de fenómenos

Más allá de politizar la naturaleza, reinscribirla en la ciudad o desanclarla de lo binario mediante la noción de socionaturaleza -portmanteau que señala la insuficiencia de una explicación social de la urbanización-, la EPU también ha servido para avanzar en la comprensión de las ciudades como ensamblajes híbridos. A saber, entramados socionaturales -a decir de la EPU-, "en parte naturales/en parte sociales, en parte técnicos/en parte culturales, pero sin unas fronteras claras" (Heynen, et al., 2006: 11), que permiten cuestionar aquellas aproximaciones que en el caso del espacio público introducian una cisura entre lo social, lo infraestructural y lo natural. Es en este sentido que debe ser entendida la apelación a la ampliación de la ecología política urbana utilizada en este texto; ni más ni menos que como una apertura hacía la hibridez, fuertemente comprometida con la proliferación del abanico de actores heterogéneos que integran el espacio público.

14 Otro de los giros metodológicos de la ANT -véase: Latour (2004b, 2008)- es el que invita a desplazar el foco de la discusión desde las cuestiones de hecho -aparentemente incontrovertibles y autoevidentes, con frecuencia fijadas por los medios de comunicación, las fuerzas del mercado o el Estado-, hacia las cuestiones de interés que, con más o menos protagonismo, involucran formas de vida, relaciones, necesidades, deseos y debates imprescindibles para la existencia de las cuestiones de hecho pero que, mayoritariamente, suelen verse arrinconadas por ellas. 
invisibilizados y excluidos" (Thrift, 2004: 84), el análisis de las cuestiones de hecho -que aunque se pretendan críticas y radicales asumen unas condiciones de posibilidad dadas- no debería ser el principal objeto de una geografía considerada ni crítica ni radical. Como advertían Deleuze (1996), Foucault (1999) o Latour (2004b), el cometido de las perspectivas críticas no era el juicio del mundo sino el compromiso con la "multiplicación de sus signos de existencia" (Foucault, 1999: 220) tratando de proporcionar articulaciones alternativas. No criticar, no juzgar, sino detectar y ampliar agencias, prácticas, relaciones y cuestiones; parafraseando a Latour (2008: 86): "estas son las Leyes y los Profetas".

\section{Menos criticar y más reensamblar}

La constatación de que la mayoría de las perspectivas críticas del espectro académico sufrían una suerte de anemia que lastraba sus capacidades -tanto para plantear nuevas preguntas, como para dar cuenta de los avatares, asimetrías e innovaciones del mundo desde posiciones ajenas a los marcos autorizados- condujo a Latour (2004b) a plantear una alternativa a partir de la noción de gathering (traducible como reunir, agrupar o congregar). Desde esta perspectiva, una aproximación crítica no sería aquella que se debruza en el combate de una cuestión de hecho -arrojando una visión alternativa desde una atalaya privilegiada-, sino la que se compromete con aquellas cuestiones de interés en las que se encuentran muchos de los actores partícipes de las cuestiones de hecho que se desestiman en los relatos hegemónicos - procurando, además, un foro para discutir sobre aquellos asuntos opacos o menores -:

"A pesar de sus esfuerzos, la crítica no ha sido lo suficientemente crítica. No consiste en sobrevolar las condiciones de posibilidad de una cuestión de hecho, ni en la aportación de algo más humano que se le haya escapado a las inhumanas cuestiones de hecho. Es una indagación múltiple que busca detectar cuántos participantes están reunidos en torno a una cosa, haciendo que esta exista. (...). El crítico no es aquel que critica, sino aquel que ensambla, no es el que desestabiliza las creencias de unos ingenuos creyentes, sino aquel que proporciona a los participantes un espacio para reunirse" (Latour, 2004b: 232-245256; traducción propia).

La fórmula de Latour para que las ciencias sociales recuperasen la iniciativa pasaba por renovar el compromiso con el empirismo ${ }^{15}$. Es decir, en lugar de alejarse de los fenómenos para poder criticarlos -pasándolos por el tamiz de unos conceptos extrínsecos que les quitaban realidad-, Latour sugería hacer el camino inverso: acercarse a ellos tanto como se pudiese -agregándoles realidad-, multiplicando sus posibilidades y generando nuevas asociaciones y relaciones, tanto conceptuales como políticas. Si lo visto hasta ahora puede resultar abstruso, el trabajo del geógrafo británico Colin McFarlane (2011a) posiblemente ayude a entender mejor las cosas. En su investigación sobre asentamientos informales en Mumbai, McFarlane abordó una gran controversia relacionada con la escasez de agua. Mientras que el Estado y los medios de comunicación culpabilizaban de la escasez a los habitantes de los asentamientos -acusándolos de robar y malgastar agua-, McFarlane, en lugar de plegarse a los términos señalados por los actores dominantes -

El empirismo radical o segundo empirismo impone un criterio de prudencia, profundamente constructivista, que previene contra la aceptación acrítica de lo que son los fenómenos: "el segundo empirismo no se ve para nada como el primero: su ciencia, su política, su estética, su moral son diferentes de los del pasado. Sigue siendo real y objetivo, pero es más vivaz, más conversador, más activo, pluralista y más mediado que el otro" (Latour, 2008: 167). 
decantándose discursivamente por uno de los dos lados-, condujo sus indagaciones hacia diferentes cuestiones de interés que señalaban otros sentidos de la controversia y problematizaban su supuesta autoevidencia. Además, a medida que se recorrían, las cuestiones de interés hacían proliferar todo tipo de agencias -humanas y no humanas- y formas de vida que, más allá de poner en evidencia la complejidad interna, exigían un compromiso investigador que ya no se podía limitar a denunciar un fenómeno y enunciar una crítica:

"una multitud de cuestiones de interés - debates sobre la capacidad del estado, la privatización del agua y las prácticas corruptas; cuestiones de derechos y ciudadanía; condiciones de la canalización y niveles de precipitación durante el monzón; etc.- son ignoradas de una u otra manera en la constitución de un 'hecho'. Sin duda, criticar estas cuestiones es importante, pero ¿cómo podemos generar nuevas asociaciones en torno al agua? (...). No podemos limitarnos a criticar esas desigualdades urbanas; debiendo trazar, ensamblar y generar nuevas formas de asociación y espacios para la elaboración política" (McFarlane, 2011a: 213-214).

Pues bien, ¿cómo afecta todo este entramado de propuestas y conceptos sugeridos desde las filas de la ANT y la NRT a las políticas del espacio público y a los estudios de la ciudad? ¿De qué manera es posible avanzar hacia una noción de espacio público no representacional, menor, descajanegrizado e interesante que permita lidiar mejor con lo múltiple, lo híbrido, lo diferente, lo insospechado y lo afectivo? ¿Cómo pueden contribuir estos debates a la reavivación de un objeto de estudio que se había vuelto tan redundante en sus propuestas como insuficiente ante los retos planteados en la crisis de representación?

Lejos de una definición fáctica, dada a conceptualizar el espacio público como una realidad dada -notoriamente humana, claramente delimitada y mayormente simbólica-, este objeto de estudio puede ser reformulado a través de un artilugio conceptual -relacional y constructivistaconocido como ensamblaje (Farías, 2010, 2011a; McFarlane, 2011a, 2011b; Anderson y McFarlane, 2011). Si las perspectivas hegemónicas -tanto las más académicas como aquellas asunciones positivistas que suelen nutrir las políticas públicas y las estrategias de diseño urbano- habían asumido que el espacio público era un receptáculo autoevidente ${ }^{16}$ y una suerte de objeto geométrico y estático que alojaba la vida social; las aproximaciones propiciadas por la noción de ensamblaje lo ven como un efecto relacional -un logro múltiple, híbrido, emergente y descentrado que se ensambla "simultáneamente [y] de múltiples maneras (...) en distintas redes de prácticas" (Farías, 2011a: 29). Es decir, en vez de una forma espacial capaz de contener lo urbano -cuando menos alguna de sus representaciones sociales, simbólicas y antropocéntricas-, el espacio público pasaría a concebirse como una realidad múltiple y fuertemente distribuida que se actualiza en el constante devenir de una infinidad de prácticas, mediaciones y formas de vida, cuyas dinámicas no solo exceden sus aparentes límites espaciales, sino que también evidencian una mayor simetría de las agencias que tienen lugar.

Como una llave maestra dispuesta a enfrentarse a cualquier cerradura representacional, el ensamblaje interrumpe una regla metodológica agotada -la que conducía a geógrafas y geógrafos a la verificación o rechazo de una serie de premisas dadas de antemano y acomodadas en una

16 Para una revisión del concepto de espacio público en geografía véase: Estévez (2012). 
organización dicotómica de la realidad-, en favor de una apertura hacia lo incierto y lo desconocido -lo heterogéneo y lo múltiple-, mediante un esfuerzo innovador que no solo identificaría posibles no prescritos en dinámicas preconcebidas sino que también ayudaría a crearlos. Sin duda, la predisposición de la perspectiva de los ensamblajes a situarse a merced de cuestiones, entidades y fuerzas menores, interesantes e insólitas -exteriores a la representación-, dota a los investigadores de una sensibilidad que nos orienta hacia la creación de nuevas articulaciones del mundo, antes que a la extracción de representaciones. Por lo tanto, en lugar de un escenario domesticado, euclidiano, y habitado exclusivamente por acuerdos y desacuerdos humanos; a la luz de los ensamblajes, el espacio público remite a una multiplicidad de articulaciones heterogéneas y a las capacidades emergentes de dichas articulaciones. Pero además, los ensamblajes permiten pensar políticamente las articulaciones; no solo por propiciar una toma de conciencia de la complejidad del espacio público que promueve su interés y evaluación, sino por señalar que este también depende de un "trabajo de composición" (Farías, 2011a: 28) de dicha complejidad. En efecto, las decisiones que se toman a este nivel tienen efectos profundos en "las formas de convivencia entre distintos tipos de objetos y agentes" (Farías, 2011a: 28) y, en consecuencia, evidencian un poder significativo sobre qué formas de vida y qué tipo de relaciones se favorecerán políticamente a través de decisiones aparentemente técnicas. Ahora bien, como señala el propio Farías -citando el trabajo de Mol (2002)-, es importante percatarse de lo que realmente indica la idea de multiplicidad. A pesar de lo que pudiese inducir el sentido común, la multiplicidad no apela a la diversidad del espacio público sino a su multiplicidad ontológica: señala su existencia múltiple, de muchas maneras y no siempre de forma euclidiana.

Ampliar la ecología política del espacio público y abrir sus condiciones de posibilidad como objeto de estudio me condujo a entenderlo como un ensamblaje urbano; un entramado de relaciones más o menos conflictivas y polémicas, un objeto heterogéneo, un efecto relacional, emergente, múltiple en términos ontológicos, y, sobre todo, como una realidad tan incierta como controvertida y descentrada. Si, como apuntaba Farías (2011b: 366), anticipar el tipo de entidades, actores o cuestiones que deben tomarse en cuenta en el estudio de la ciudad suele ser un error -pues, a poco que uno se sumerge en el "terreno" en seguida se encontrará con grupos emergentes, muchas formas de conocimiento y programas de acción inesperados-, parece lógico hacer caso de aquella consigna latouriana que sugiere que la tarea de definir y ordenar lo social debe dejarse a los actores mismos, pues: "para alcanzar algún sentido del orden, la mejor solución es rastrear relaciones entre las controversias mismas en vez de tratar de decidir cómo resolver cualquier controversia dada" (Latour, 2008: 42).

En mi investigación sobre la plaza Lesseps de Barcelona, seguir a los actores y al tipo de controversias señaladas por ellos me llevó a estudiar diferentes redes de prácticas y formas de realidad insospechadas que ponían de manifiesto articulaciones diferentes de un mismo objeto -de una misma plaza Lesseps. Entre ellas, la disputa urbanística que abordaré en las siguientes páginas.

No obstante, antes de continuar, quisiera mostrar de manera sucinta el instrumental metodológico con que construí mi objeto de estudio. Habiendo asumido que una etnografía diseñada en sintonía con la consigna de "seguir a los actores mismos" (Latour, 2008: 28) no podría dar por hechas las entidades y colectivos que estudiaba, ni presuponer un conjunto de dinámicas relevantes que la investigación tan solo debiera localizar por medio del trabajo de campo, opté por la "cartografía de controversias" (Chinchilla y Muniesa, 2004) como guía metodológica. Fue así, centrando mi atención en la descripción de los entramados relacionales que performaban Lesseps, 
y sin restringir de manera apriorística la gama de controversias que podrían resultar interesantes para la investigación, como pude reconocer algunas de las redes de prácticas y formas de realidad que señalaban agenciamientos y dinámicas significativas para el mundo común de la plaza. Mediante un dispositivo analítico provisto de métodos y procedimientos heterogéneos como: técnicas documentales -análisis de prensa, estudio de documentación técnica y vecinal, consulta de archivos históricos o rastreo y seguimiento de la información publicada en una constelación de páginas web y redes sociales-; entrevistas en profundidad -tanto con diversos informantes clave como con miembros de la ciudadanía concernida-; o la observación participante y las prácticas colaborativas más propias de una "relación de correspondencia" (Ingold, 2014) -como la celebración de una jornada pública de debate y participación vecinal, o la elaboración de un vídeo junto a un espacio para la acogida de vecinos sin hogar-, fue posible descubrir la multiplicidad y comprometerme con algunas cuestiones de interés identificadas como, por ejemplo, la disputa alrededor del rediseño.

\section{La plaza de Lesseps, una controversia urbanística}

Además de un espacio polémico y un lugar central de la ciudad, Lesseps es una encrucijada histórica de Barcelona en la que confluyen barrios, calles, avenidas, diferentes modos de transporte colectivo, servicios sociotécnicos ubicados en su subsuelo -como las infraestructuras del metro o una central de recogida neumática de residuos sólidos urbanos-, $y$, también, una de las arterias viarias más relevantes de la ciudad -la ronda del general Mitre- que permite cruzar Barcelona por el interior -tanto de la ciudad como de la propia plaza. Está situada en un entorno territorialmente ambiguo y fronterizo de la parte alta de la ciudad, donde barrios densos y compactos se encuentran con una trama urbana deshilachada y una topografía más abrupta en la que se asientan algunos de los barrios construidos en el pie de monte de la sierra de Collserola. Pero, más allá de su complejidad territorial, en el imaginario colectivo de Barcelona, Lesseps remite a un estallido cíclico de intervenciones controvertidas, obras problemáticas y eternizantes, insatisfacción vecinal, protestas populares y ruido mediático. Estos elementos han ayudado a labrar la imagen de un espacio maldito (Solà-Morales, 2006) y azotado por una suerte de fatalismo urbano; un lugar en el que la percepción de un rehacerse tan continuo como infructuoso ha acarreado un estado de provisionalidad perpetua. En efecto, la inestabilidad morfológica, funcional y simbólica que se ha cernido a lo largo de las últimas décadas sobre la plaza, ha acabado por convertirla en una molesta piedra en el zapato de la agenda urbanística de Barcelona; como si Lesseps se tratara de un límite o un punto oscuro de un modelo urbano que no ha sabido conciliar, de manera satisfactoria, la creciente voracidad espacial exigida por el tráfico rodado, con otro tipo de responsabilidades urbanas -como el espacio vecinal y comunitario, o el histórico papel que se le atribuía a esta plaza como bisagra territorial y lugar de encuentro entre barrios.

Si bien es cierto que detallar de manera exhaustiva el intrincado historial urbanístico de Lesseps excede las pretensiones de este texto (para una explicación minuciosa véase: Estévez, 2014), resulta imprescindible señalar algunas de las vicisitudes de su proceso de remodelación más reciente para facilitar la comprensión del litigio de que es objeto el artículo.

El último gran episodio de disputa de la plaza se desencadenó en la primera década de este siglo, a raíz de la presentación pública el 21 de enero de 2002 de un proyecto de remodelación 
que los vecinos esperaban con impaciencia desde el año 1996, cuando se hizo público el acuerdo tomado por el conjunto de fuerzas políticas con representación en el Consejo del Distrito de Gracia, en el que instaban a acometer una reforma global de la plaza. Inscrito en una estrategia municipal de reconquista urbana (Sanfeliu, 2003; Borja, 2010) que pretendía cerrar algunas de las heridas que el urbanismo franquista había infligido en la ciudad -y de cuyo muestrario Lesseps constituía uno de sus mayores despropósitos desde la década de $1970^{17}$-, el proyecto, firmado por el estudio del prestigioso arquitecto barcelonés Albert Viaplana, perseguía la reparación de las vecinas y vecinos, $y$, a su vez buscaba poner fin a un período de más de dos décadas en el que la formalización de la plaza había logrado identificar un lugar céntrico y emblemático de Barcelona con la deshumanización, la invasión y dominio del tráfico rodado y la desposesión urbana. Sin embargo, la propuesta anunciada por el Ayuntamiento, lejos de obtener la recepción entusiasta y celebratoria imaginada, se dio de bruces con la oposición de un movimiento urbano, tremendamente renovador en el despliegue de su repertorio de acción colectiva, que alteraría el curso de acción previsto por las autoridades municipales.

El mantenimiento de un polémico desnivel que se había erigido como uno de los principales estigmas del desastre urbanístico de Lesseps, echaba por tierra parte de las promesas electorales y los compromisos políticos acordados años antes, relativos a la superación del sobrevenido carácter fronterizo de la plaza, la restitución de su pendiente natural, la reducción del tráfico rodado y la reconquista vecinal y ciudadana del espacio público.

Ahora bien, la controversia abierta en el invierno del 2002 iba mucho más allá de un mero conflicto urbanístico y, como muestra de ello, las vecinas y vecinos -que en seguida constituyeron la plataforma Una altra plaça Lesseps és possible- no se limitaron a rechazar los términos de la propuesta del Ayuntamiento, ni a esperar de brazos cruzados por la llegada de una alternativa mejorada en los despachos, más respetuosa con las directrices consensuadas a finales de los años 90. Al contrario, lo que la movilización vecinal de Lesseps acabaría poniendo de manifiesto serían dos cosas de mucho calado. La primera, ni más ni menos, apuntaba hacia la manera de gobernar la ciudad según una lógica representativa, tecnocrática y jerárquica. En efecto, la polémica generada permitía entrever algunos de los síntomas de una crisis de la representación -de la representación moderna del mundo (Latour, 2004a)- que, en primer término, señalaba el agotamiento de los mecanismos de toma de decisión convencionales. La segunda no dejaba de ser una consecuencia de la primera y señalaba la disputa sobre la representatividad de los portavoces de Lesseps. Es decir, lo que planteaba la controversia ${ }^{18}$, más allá de una cuestión urbanística que se pudiese resolver con una u otra acción de carácter técnico, era la capacidad de dilucidar quién podía hablar y decidir legítimamente en nombre de Lesseps.

De esta manera, además de denunciar los aspectos técnicos y formales del proyecto que desestimaban los acuerdos previos, la reivindicación vecinal ponía en escena una demanda, en cierta

\footnotetext{
Una de las consecuencias de esta denostada actuación, más allá de la transformación de un espacio vecinal en un potente nudo de tránsito rodado trufado de viales, fue la profunda alteración topográfica de la plaza al hacerse pasar la ronda del general Mitre por su interior en forma de paso inferior a cota sobrelevada.

18 En el repertorio conceptual de la ANT, el término controversia cuenta por lo menos con dos sentidos. Por una parte, designa un escenario de litigio y desacuerdo en el que los conocimientos técnicos y científicos no solo no son capaces de reducir las dudas, sino que suelen amplificarlas. Por otra parte, señala una lucha por la representatividad de un portavoz, un desacuerdo sobre la capacidad de un actor de hablar y decidir en nombre de otro(s).
} 
medida insólita, que cogería al Ayuntamiento con el pie cambiado; sin la activación de formas de decisión menos jerárquicas y más colaborativas, la controversia abierta no podría cerrarse ${ }^{19}$ y la transformación urbana de Lesseps no lograría el consenso.

El convencimiento vecinal de que algunas de las decisiones técnicas que integraban la propuesta del Ayuntamiento se habían tomado en medio de la incerteza -cuando no parecían meras argucias, enmascaradas de obligaciones técnicas, que buscaban abaratar costes o rehuir desafíos más complejos-; junto al hecho de que para las vecinas y vecinos movilizados la separación moderna entre la representación de las cosas y la representación de las personas parecía no tener ya mucho sentido en aquella tesitura, comportó diferentes transgresiones. Una parte importante del vecindario de Lesseps ya no estaba dispuesta a aceptar sin más la delegación del saber y del poder en sus respectivas instancias representativas, como tampoco aceptaban que las cuestiones técnicas pudiesen ser tratadas como elementos neutros, indiscutibles y, en consecuencia, fuesen eximidas del escrutinio ciudadano. Los mecanismos convencionales de exposición pública y de presentación de alegaciones ya no eran suficientes, y los vecinos ya no se conformaban con un papel secundario de legitimadores finales de las decisiones tomadas en los despachos de los diferentes departamentos de urbanismo y/o en confinados estudios de arquitectura e ingeniería.

El conflicto de Lesseps mostraba cómo una parte creciente de la ciudadanía ya no admitía que los expertos y los políticos profesionales decidiesen en su nombre sobre proyectos que afectaban a su vida cotidiana, especialmente cuando estos tenían lugar en un contexto de desconfianza o incertidumbre. De este modo, lo que acabó por desvelar el desacuerdo fue una aspiración ciudadana -todavía embrionaria-, que ponía de manifiesto un deseo de participación activa en los procesos de deliberación y decisión de todo aquello que concerniese a los vecinos y despertase algún tipo de incerteza. Es decir: nihil de nobis, sine nobis.

\section{Participación ciudadana, crisis y desbordes de la representación: tra- ducir Lesseps}

Presionado por una movilización vecinal que exigía más y mejor democracia en la producción de la propuesta de remodelación de la plaza, el Ayuntamiento de Barcelona optó por poner el proyecto en cuarentena, aviniéndose a negociar con los vecinos movilizados y con otros portavoces políticos y expertos que en seguida se asomaron a la controversia. Así fue cómo comenzó a tomar cuerpo un inédito proceso de participación ciudadana en cuyo seno se articuló la Comisión Mixta $(\mathrm{CM})^{20}$ : una instancia de mediación que nacía el 12 de marzo de 2002 con el objetivo de abordar, de manera conjunta, una propuesta consensuada que garantizase un clima de acuerdo para la remodelación de la plaza. Sin lugar a dudas, la CM suponía una primera victoria de los vecinos ante el Ayuntamiento que, consciente de la inexorabilidad de la negociación de las cuestiones más controvertidas del proyecto, optó por abrirse a un proceso dialógico que, en cualquier caso, pa-

19 Según Michel Callon (1995), una condición imprescindible para conseguir el cierre de las controversias es el acuerdo unánime sobre el estatus de los portavoces como tales: “La realidad social y natural es el resultado de una negociación generalizada sobre la representatividad de sus portavoces. Si se logra el consenso, los márgenes de maniobra de cada entidad quedarán estrechamente delimitados (...). Una controversia es el conjunto de declaraciones mediante las cuales se cuestiona, discute, negocia, rechaza, etc. la representatividad de un portavoz. (...). El cierre ocurre cuando los portavoces son unánimemente considerados como tales más allá de toda duda" (Callon, 1995: 274-275).

20 Además de portavoces vecinales, representantes políticos y técnicos municipales, la CM estaba integrada por tres "técnicos independientes" que habían sido propuestos por la plataforma vecinal para ejercer de árbitros, mediadores y vigilantes de la controversia. 
recía más orientado a la traducción ${ }^{21}$ y el enrolamiento del vecindario disconforme que a la experimentación democrática. Ahora bien, como espacio de negociación y deliberación, la CM creaba un lazo que no existía con anterioridad y desplazaba las posiciones iniciales. En efecto, esta nueva entidad ya no se comportaría como un organismo meramente municipal -como habían hecho hasta entonces los técnicos del departamento de urbanismo, los arquitectos que habían diseñado el proyecto o los responsables y portavoces políticos-, ni como un colectivo exclusivamente vecinal; al contrario, la Comisión Mixta irrumpía como un artefacto híbrido que, de alguna manera, problematizaba la distribución previa de jerarquías, conocimientos y saberes de los participantes.

\section{Foros híbridos. Democratizar la democracia en Lesseps}

La coincidencia de esta heterogeneidad de actores con intereses y puntos de vista diferentes, cuya principal característica residía en el hecho insólito de que especialistas y profanos, vecinos y políticos compartían un mismo espacio de discusión, tiene algunos puntos en común con una serie de experiencias colaborativas, entre expertos y legos, que han proliferado a lo largo de las últimas décadas. Una serie de fenómenos que Callon et al. (2009) han conceptualizado y estudiado con el nombre de foros híbridos ${ }^{22}(\mathrm{FH})$, y que han hecho tambalear algunos de los aspectos más agotados de los mecanismos de toma decisión de las democracias representativas. Los ejemplos abordados por estos autores suelen tratarse de iniciativas ciudadanas, protagonizadas por grupos de personas afectadas por controversias sociotécnicas, ambientales o sanitarias que, para reducir la incerteza del fenómeno que les afecta, deciden organizar por su cuenta un espacio para el debate, la investigación y el aprendizaje. Su objetivo es obvio: reducir el umbral de incerteza, obtener información precisa, y ejercer su derecho a decidir sobre el fenómeno que los afecta y preocupa -una situación en la que ni la mera lógica experta, ni la autoridad de sus representantes políticos parecen ayudar a resolver nada.

Ahora bien, más allá de una cuestión de sofisticación procedimental, el principal rasgo de los FH no radica tanto en su condición de inmaculados espacios para el diálogo como en el logro de una dinámica efectivamente híbrida capaz de problematizar algunos aspectos de las identidades de los convocados que podrían obstaculizar la construcción colaborativa del consenso. Suspender o, cuando menos, cuestionar la distribución de roles previa, es un elemento imprescindible para que el $\mathrm{FH}$ pueda imaginar y construir un mundo en común que no emane de la suma de perspectivas jerarquizadas, sino de un diálogo inédito entre iguales que apueste por la simetría de saberes $^{23}$ y la articulación de una experticia común. Si esta lógica igualitaria prevalece, los conocimientos expertos dejarán de funcionar como lo han hecho tradicionalmente; a saber, imponiendo de manera categórica -y liberados del debate político- cuestiones aparentemente

\footnotetext{
La traducción es una de las principales herramientas conceptuales de la ANT. Callon y Latour (1981) la definieron como un proceso cargado de actos de negociación, persuasión, intriga y violencia, gracias a los cuales un actor logra que se le confiera la autoridad necesaria para hablar o actuar en nombre de otros actores, convirtiendo sus propuestas en punto de paso obligado del conjunto de actores o fuerzas concernidas. Este proceso de problematización, interesamiento y enrolamiento de otros actores y entidades, permite concebir el ejercicio del poder como un proceso heterogéneo orientado a la alineación/ensamblaje de una multitud de entidades y relaciones heterogéneas en un mismo entramado.

22 Los llaman "foros" porque se trata de espacios abiertos, organizados para el debate de cuestiones controvertidas, e "híbridos", tanto por su composición -conformados por un abanico de actores heterogéneos: expertos, políticos, técnicos y ciudadanía afectada, cuya coincidencia altera las fronteras convencionales entre expertos/profanos, políticos/ciudadanía-, como por los temas que suelen abordar -cuestiones de naturaleza heterogénea y controvertida que son tratadas desde muchos puntos de vista: técnicos, políticos, éticos, económicos, etc.

${ }_{23}$ En efecto, iguales no significa equivalentes, ni pretende volver intercambiables formas de experticia diferentes, más bien señala una "puesta en igualdad" (Domènech y Tirado, 2011: 48) de expertos y profanos, representantes y representados que implica una problematización de roles.
} 
neutras que tienen implicaciones para todos los actores concernidos. Esto no quiere decir que los experimentos de democracia dialógica nieguen o menosprecien el valor de los conocimientos expertos, al contrario, lo que persiguen es democratizarlos, pasándolos por el filtro de la política; justo lo que estos solían saltarse o cancelar a través de su autoridad. Es por este motivo que, en la lógica del $\mathrm{FH}$, la razón experta pierde su centralidad y deja de funcionar como proveedora de una verdad universal e indiscutible. Es decir, tanto las soluciones discutidas, como el logro del consenso ya no dependerán del dictamen de una experticia particular que defina en exclusiva los términos objetivos del debate. En un elogio democratizador, aquellas cuestiones que solían decidir los expertos tendrán que confrontarse y validarse al fragor del debate, en presencia de todos los participantes. Y, evidentemente, en el transcurso de la controversia, algunas de las cuestiones aparentemente objetivas e inapelables pueden acabar experimentando cambios que ponen de manifiesto tanto la porosidad de la frontera entre hechos y valores, como el trasfondo político de algunas decisiones técnicas y la supuesta neutralidad de los expertos.

A mi juicio, buena parte de las características que identifican estos espacios guardan fuertes similitudes con el proceso de participación de Lesseps y la creación de la CM. En primer lugar por la composición heterogénea de lo que no es sino una instancia de diálogo y colaboración de actores muy diversos, pero, también por las vicisitudes de su origen. La Comisión Mixta no nació en Lesseps como un instrumento promovido por la administración pública para, en primer lugar, tratar de concertar con los portavoces vecinales el fondo y la forma de una actuación tan deseada como necesaria. Justo al contrario, surgió como respuesta a una movilización ciudadana que exteriorizaba una evidente desconfianza hacia el poder político y la autonomía de los conocimientos expertos; y que, a su vez, manifestaba la "crisis sostenida de legitimidad" (Graña, 2005: 125) que sufren los mecanismos de decisión convencionales de las democracias representativas.

Como apuntan Callon et al. (2009) los foros híbridos forman parte de un proceso de cuestionamiento y superación de dos asimetrías muy características de la modernidad occidental que habrían sostenido con éxito el funcionamiento de nuestras democracias hasta su crisis actual. Conviene tener en cuenta que (véase Latour, 2007a) la modernidad surgió como un mecanismo esencializador que, en su propósito de llegar a una verdadera esencia de las cosas, impuso una lógica dicotómica que organizaba el mundo en dos zonas ontológicamente distintas. Por una parte, la naturaleza -el ámbito de la objetividad y los hechos, representada por la ciencia-, y por otra parte la sociedad -el ámbito de la subjetividad, los valores y las opiniones, representada por la política. Según la "constitución moderna" (Latour, 2007a: 33) estas dos esferas tendrían que existir segregadas, cada una con sus procedimientos e instituciones de legitimación. Así, la ciencia, como representación de la naturaleza y de lo no humano, debía elaborar el conocimiento objetivo e indiscutible en laboratorios y estudios aislados de toda influencia ajena a su dominio. Y a su vez, la política, como representación de la sociedad, debía tomar decisiones, con valores y opiniones, en los parlamentos y otras instituciones similares, sin decir ni mu sobre los no humanos movilizados por la ciencia. Como consecuencia de esta concepción del mundo, Callon et al. (2009: 158) entienden que las democracias representativas son responsables de la creación de nuevas asimetrías mediante la aplicación de una "lógica de doble delegación" que vertebraba los términos de las relaciones de las personas con el poder. Por una parte, la ciudadanía delegaba la elaboración del conocimiento en las personas expertas -lo que creaba una primera asimetría entre expertos y profanos-, y, por otra parte, delegaba la capacidad de decidir sobre lo común en sus representantes políticos -generándose la segunda asimetría entre políticos profesionales y el común de la ciudadanía. Precisamente, los FH desafían la lógica de la doble delegación y desbor- 
dan las asimetrías generadas por las democracias occidentales, evidenciando una profunda crisis de representación ante un deseo de más y mejor democracia.

Con la perspectiva de los FH, la experiencia de la Comisión Mixta puede pensarse de manera compleja. Aquella instancia de diálogo nacida de la movilización vecinal y orientada a la articulación de una propuesta de remodelación consensuada, podría haber desbordado las intenciones del ayuntamiento -el enrolamiento de los vecinos en su propuesta como garantía de una traducción exitosa-, y trazar una línea de fuga que profundizara en una pionera experiencia de democracia dialógica en Barcelona. Ahora bien, para confirmar este extremo era necesario que la $\mathrm{CM}$ se hubiese esmerado en nivelar las relaciones de poder, particularmente aquellas que podían mantener las jerarquías entre expertos y profanos. Dicho con otras palabras, si se pretendía que los actores partícipes coprodujesen de manera colaborativa la otra plaza posible, el espacio de las negociaciones tendría que haber establecido condiciones de máxima apertura y simetría para el diálogo y la experimentación colectiva; esto es: la puesta en igualdad.

La Comisión Mixta comenzó a reunirse en la segunda quincena del mes de abril de 2002, y, teniendo en cuenta el tipo de cuestiones que se discutían en su seno, parecía que la dinámica del FH se imponía, a pesar de los recelos iniciales de los portavoces de la administración. Uno de los primeros temas a debate, el desnivel que se mantenía en el proyecto debido a la supuesta inalterabilidad de las losas de cubrición del túnel de la ronda que había desfigurado Lesseps en los años 1970, demostraba que la frontera entre hechos y valores había saltado por los aires en el conflicto. Es decir, ya no había nada exclusivamente técnico o de dominio exclusivo de los expertos que pudiese esquivar la política. Las losas de hormigón que cubrían el túnel de la Ronda del General Mitre eran por así decirlo algo tan social como el deseo de reconquista y disfrute de un espacio de encuentro vecinal.

Sin embargo, a finales de mayo, cuando ya se habían celebrado cuatro sesiones de la CM, sus integrantes decidieron crear una Subcomisión Técnica (ScT) integrada únicamente por personas expertas. A partir de este momento, los arquitectos municipales, el estudio de arquitectos redactor del proyecto, tres miembros de la plataforma vecinal Una altra plaça Lesseps és possible que eran arquitectos de profesión, y los técnicos independientes, serían las personas en las que la CM delegaba la discusión de las cuestiones de carácter técnico. Los trabajos de la ScT dieron lugar a un borrador en el que se proponían una serie de orientaciones para la remodelación de la plaza que pretendían vehicular las principales reivindicaciones vecinales. Ahora bien, esta delegación en los expertos alejó la experiencia de Lesseps de las virtudes de los foros híbridos. Fue aquí cuando la controversia -que había logrado reunir portavoces muy heterogéneos en una misma sala, involucrando expertos y profanos, representantes políticos y ciudadanos en un experimento colectivo orientado a la exploración conjunta de otra plaza posible- dio un paso atrás en su radicalidad democrática, rehuyendo el reto de superar una de las asimetrías más características de las democracias representativas -la que separaba expertos y profanos y simplificaba las formas de experticia. En lugar de hacer todo el camino juntos -a pesar de que ello lo ralentizase, y obligara a los expertos a deshacerse en explicaciones y negociaciones de sus propuestas, dibujos y cálculos-, la creación de la ScT puso límites a la hibridez y frustró una dimensión clave del desafío dialógico.

En paralelo, Lesseps dejó de imaginarse, explorarse y componerse como un mundo en común -en el que múltiples formas de su realidad podrían emerger y hacerse un hueco en el diseño de la plaza. Además, la rehabilitación de la asimetría expertos/profanos contribuyó a atomizar y dis- 
persar las maneras de pensar la plaza, favoreciendo la aparición de un clima de crispación, tanto entre la plataforma vecinal -en la que afloraron rumores, sospechas y acusaciones entre diferentes sensibilidades-, como en la propia ScT -donde el tira y afloja que mantenían los técnicos con filiación vecinal y los portavoces del Ayuntamiento no parecía encontrar una salida.

Ante una situación que amenazaba con hacer descarrilar el proceso, la técnica independiente Itziar González dispuso sus habilidades de arquitecta-cuidadora (Gil-Fournier, 2012) y propuso otro desplazamiento del conflicto a través de una nueva mediación que pretendía introducir criterios de proximidad, responsabilidad y cuidado. Consciente de que sin una incorporación efectiva de los vecinos y vecinas ninguna solución experta -por ambiciosa, acertada o elocuente que fuese-, lograría ganar la legitimidad necesaria para restablecer el consenso, González apostó por colaborar en el empoderamiento de las perspectivas vecinales mediante la organización de unas jornadas participativas abiertas a la ciudadanía.

Los días 9, 10 y 11 de septiembre de 2002, la iglesia de los Josepets de Gracia alojó un experimento de urbanismo participativo que, además de pretender sumar al máximo de vecinos posibles a la discusión que habían mantenido los expertos, buscaba someter a escrutinio popular el borrador elaborado por estos. Un equipo integrado por cinco jóvenes arquitectos, un antropólogo y una geógrafa atendió a más de tres centenares de vecinos que se acercaron a solicitar información, expresar su parecer o sugerir alguna idea.

Las paredes de la iglesia de los Josepets volvían a reunir lo que la ScT había separado -expertos y profanos. Ahora bien, nuevamente, el reparto de roles se mantenía intacto, lo que quería decir que mientras que las personas expertas contribuían con sus conocimientos objetivos y estructurantes, los vecinos y vecinas colaboraban con deseos, opiniones y experiencias ${ }^{24}$ que podían ayudar a confrontar, o, como mucho, enriquecer una razón técnica cuya incontrovertida autoridad permitía que los expertos siguiesen hablando en nombre de la objetividad y, por tanto, pudiesen definir en exclusiva las condiciones de posibilidad de la plaza. Además de las explicaciones técnicas, diálogos, consultas y propuestas, este experimento contaba con una actividad que a la postre sería la más característica del proceso. Todas las personas que se acercaban a las jornadas eran invitadas a dibujar sobre un plano de la plaza las trazas de sus itinerarios cotidianos posibles y deseados sin tener en cuenta los obstáculos que habían hecho de Lesseps una frontera incómoda.

Trayectos cotidianos, niveles de pendientes aceptables, pacificación o soterramiento de la ronda, ensanchamiento de las aceras, número de losas que habría que desmontar, etc.; para que aquella retahíla de ideas, experiencias, demandas y sugerencias no cayesen en saco rato, González ideó una metodología que buscaba un compromiso con las demandas de todo el mundo.

Vaciando sistemáticamente toda la información -trazados, sugerencias, críticas- que las participantes -identificadas con nombre, domicilio y tipo de vínculo con la plaza- habían proporcionado, el equipo de González produjo una serie de planos en los que se detallaba la propuesta ema-

En un artículo publicado por Itziar González en el suplemento de cultura de un conocido diario local lo expresaba de esta manera: "Los arquitectos e ingenieros compartieron con ellos todo lo que era 'técnicamente' posible y ellos aportaron todo lo que era 'deseable' tras su atenta y larga observación de años" (González, 2003: 17). 
nada de la participación. Estos planos dieron lugar al documento Nous criteris per a la reforma de la plaça Lesseps. Memòria, documentació $i$ conclusions obtingudes a partir del proces participatiu dut a terme els dies 9, 10 i 11 de setembre de 2002 (González et al., 2002) que, después de largos debates, fue aprobado por la Comisión Mixta. Uno de estos planos, el "plano del compromiso", sintetizaba las demandas de la plataforma vecinal y añadía otras que se habían identificado en las jornadas de participación.

El 18 de diciembre de 2002 la CM instaba al equipo de Albert Viaplana a retomar la redacción del proyecto integrando una serie de demandas vecinales que pocos meses antes resultaban poco menos que imposibles a juicio de los representantes. A saber, la reducción de viales y del tráfico rodado, la recuperación de la pendiente natural de la plaza o la mejora de la conectividad entre los barrios de los alrededores y un nuevo diseño para la plaza que priorizase su dimensión de lugar de encuentro. Además, el acuerdo proponía la constitución de una Comisión Mixta de Seguimiento (CMdS) que, durante la fase de redacción, velaría por el cumplimiento de todos aquellos criterios rectores de la reforma que habían sido consensuados. La CMdS se reunió en seis ocasiones en las que los portavoces vecinales trasladaban al equipo de Albert Viaplana diferentes demandas y sugestiones que, como si se tratara de un pedido a la carta, el arquitecto cocinó con total libertad, según el lenguaje, los recursos y los elementos más característicos de su arquitectura.

El 10 de diciembre de 2003, Josepets acogía el acto de presentación del nuevo proyecto de remodelación. Una sobria maqueta de madera y un conjunto de planos detallaban las nuevas cotas y pendientes, y daban cuenta de una propuesta que integraba la mayoría de las reivindicaciones. Además, un amplio abanico de autoridades municipales, miembros de las entidades vecinales, ciudadanos del común, integrantes del estudio de Albert Viaplana y técnicos independientes, celebraban y ponían en escena el logro del consenso que aseguraba el cierre de la controversia. Después de muchas vueltas, los vecinos desplazados a la iglesia de los Josepets estaban del lado del proyecto de remodelación de la plaza. El arquitecto y el Ayuntamiento volvían a considerarse portavoces legítimos de Lesseps, y tanto la maqueta como los documentos exhibidos testimoniaban la traducción. Después de largas y complejas negociaciones, los intereses de los vecinos se veían representados por primera vez en el lenguaje del arquitecto a través de aquella maqueta. Todo hacía prever el cierre de la controversia y como colofón, el 19 de diciembre, una asamblea de la plataforma Una altra plaça Lesseps és possible ratificaba de manera rotunda la nueva propuesta.

Sin embargo, a lo largo del 2008, cuando las obras encaraban su fin y diferentes aspectos del diseño y la formalización arquitectónica se hacian visibles, el proceso de traducción de Lesseps exhibió con toda crudeza su naturaleza precaria. Un sector de vecinos y vecinas, además de periodistas y técnicos, pusieron en cuestión los acuerdos alcanzados con anterioridad, negando la representatividad de los portavoces vecinales y volviendo a abrir un episodio de controversia. Toda aquella heterogeneidad de elementos que se habían podido alinear en un largo y complejo proceso de traducción; a saber, la negociación sobre las losas de cubrición de la ronda, la supresión de la práctica totalidad de los obstáculos que habían fragmentado el espacio, la reducción y ralentización del tráfico en superficie, el incremento de espacio destinado a los vecinos, etc. se veía amenazada por la disidencia de un grupo de vecinos y vecinas que decían sentirse estafados y que decidieron abandonar el consenso. La práctica unanimidad exhibida cinco años antes en la presentación del proyecto era historia y Lesseps volvía a ser un objeto de desacuerdo y disputa, en el que el derecho a hablar en nombre de la plaza se ponía de nuevo en cuestión. Tanto, que 
hasta los portavoces vecinales que habían logrado figurar como representativos en la fase final del proceso de participación eran deslegitimados por un sector de vecinos que a la par que los desacreditaban, performaban su propia identidad de nuevos portavoces de Lesseps.

\section{De "otra plaza Lesseps es posible" a una plaza de posibles restringidos}

Una altra plaça Lesseps és possible, la consigna y eslogan con que un grupo de vecinas y vecinos de Lesseps decidieron organizar la resistencia al proyecto de remodelación presentado por el Ayuntamiento en el año 2002, no solo había servido de lema con que enunciar y poner en escena el conflicto; también, permitió esbozar un horizonte virtual ${ }^{25}$ para la plaza. En efecto, para los vecinos movilizados, la otra plaza Lesseps posible ya existía de manera virtual -en sus agenciamientos colectivos de enunciación: deseos, documentos, propuestas y, sin duda, también en las luchas y acuerdos que habían protagonizado-, de manera que tan solo había que acabar de hacerla real, esto es: efectuarla y actualizarla, componiendo un espacio público capaz de propiciar y acoger aquellas formas de vida en común que, virtualmente, permitía imaginar la consigna. Sin embargo, la formalización física y el diseño ornamental de la plaza, lejos de representar una inverosímil traducción literal de los compromisos establecidos entre las diferentes entidades y relaciones de Lesseps, parecía más bien su traición, haciendo bueno el viejo proverbio italiano traduttore-traditore. Una ornamentación de proporciones insólitas, dura, abigarrada y distante -cargada de gestos simbólicos y significados deconocidos e incomprendidos-, que parecía retar con arrogancia autoreferencial a los vecinos y vecinas, en lugar de acogerlos o de facilitar la multitud de formas vida en común necesarias, imaginadas y/o deseadas, causaba estupor e indignacion. Tal y como advertía Callon (1995) en una pieza memorable de la teoría del actor-red, toda traducción implica siempre la posibilidad de una traición: una transformación, un desplazamiento, una deriva o una invención que voltee el proceso. Ahora bien, para comprender este caso, posiblemente sea más interesante acudir a la noción de traducción sostenida por Viveiros de Castro (2010), para quien una traducción exitosa es aquella capaz de deformar el dispositivo y las herramientas conceptuales de quien se sabe traductor y/o portavoz privilegiado de un entramado heterogéneo. Trasladada a Lesseps, esta idea permite especular sobre qué debería haber pasado con el diseño de la plaza para que la traducción no hubiera fracasado. Si el arquitecto, en vez de limitarse a incorporar las propuestas y sugestiones formuladas por los vecinos a su proyecto, se hubiera dejado afectar por ellos, atreviéndose a deshacerse de algunos de los postulados y puntos de partida más recalcitrantes de su paleta, para pensar más como un vecino, tal vez los efectos de la traición no hubieran dinamitado el consenso. Con todo, más allá de contribuir a reabrir la controversia, la definición del diseño de la plaza desde un estudio de arquitectura -en vez de un foro de participación en el que se exploraran escenarios para la vida en común de Lesseps-, comportó una simplificación del espacio construido. La delegación del diseño frustró la composición colectiva de un mundo común, impidiendo que la dinámica propia de un foro híbrido continuara avanzando en el reconocimiento y la incorporación de nuevos y más portavoces de la plaza, esto es, ampliando y haciendo proliferar el abanico de actores y versiones de Lesseps que habría que movilizar y traducir, para que el proceso resultara más inclusivo y democrático. A medida que el diseño se repleglaba en manos expertas, el proyecto se alejaba de la multiplicidad, la heterogeneidad y de la posibilidad de representar y hacer convivir al máximo de formas de realidad de la plaza.

25 Sobre el par virtual/actual y su relación con "lo nuevo" en el pensamiento de Gilles Deleuze véase: Deleuze (1987: 102). 
Pero no solo el diseño arquitectónico ponía en duda la traducción de Lesseps. La problemática irrupción de lo que se conoce como el mundo subpolítico de las infrastructuras (Latour, 2007b; Domínguez y Fogué, 2013) echaría más leña al fuego -volviendo a poner sobre la mesa los límites de la cajanegrización de las cuestiones infraestructurales y de las naturalezas del espacio público. La afectación de las obras de la $\mathrm{L}^{26}$ del metro -parcialmente suspendidas tras la eclosión de la crisis financiera global, y sin una fecha de finalización a la vista, mantenía la plaza inacabada y con una superficie de $1490 \mathrm{~m}^{2}$ vallada y ocupada por una grúa-puente, diferentes construcciones provisionales y una rampa de acceso para los camiones que deberían trabajar en el túnel de la futura estación-, o los problemas ocasionados con la gestión y el mantenimiento del césped -que obligarían a cerrar durante larguísimos meses un área importante (anexa a la zona afectada por las obras de la L9) concebida como una de las principales zonas de esparcimiento-, hacían muy difícil que Lesseps lograra deshacerse del estigma de provisionalidad que arrastraba de antaño y se reensamblara con éxito.

Igual que la ANT había puesto en evidencia la heterogeneidad de entidades, objetos, fuerzas, relaciones y procesos que intervienen en la producción de un hecho científico, se podría decir que lo mismo sucede con el espacio público. A pesar de que las perspectivas mayoritarias continúan concibiéndolo como una realidad acotada y autoevidente -euclidiana, antropocéntrica y simbólica-; en Lesseps, el espacio público se revela como un objeto múltiple y descentrado, un ensamblaje en el que las agencias de una disparidad de actores -humanos y no humanos- ponen de manifiesto que el empecinamiento moderno con la purificación y la separación del mundo en esferas segregadas, choca con el carácter obstinadamente híbrido de la ciudad.

Así las cosas, lo que señalaban los posibles restringidos de Lesseps, más allá de la decepción generada por sus insuficiencias como lugar de encuentro, intercambio y convivencia, era la ausencia de una cosmopolítica urbana; esto es, el diseño de un mundo común que articulara la coexistencia de humanos y no humanos en un mismo ensamblaje a la par que construía un consenso. En efecto, un diseño arquitectónico cosmopolítico, en lugar de limitarse a operar como simple embellecedor del espacio público -reduciendo el diseño al rol de una herramienta formal, o meramente estética, orientada a realzar y puntuar una realidad autoeviente-, tendría que haber estimulado "la exploración y composición de un mundo común a partir de compromisos, uniones y relaciones entre entidades heterogéneas" (Rodríguez-Giralt, et al., 2014: 2), a sabiendas que:

"La noción de exploración debe ser entendida con cuidado, pues no se trata de conocer un mundo ya constituido y amueblado, sino de construir y componer (...), la cosmopolítica es una exploración performativa, con consecuencias ontológicas, y que implica articular las entidades y relaciones que componen el mundo" (Rodríguez-Giralt et al., 2014: 2).

\section{Reflexiones finales}

Es el momento de volver al inicio del texto. La inminente reurbanización de la superficie de Lesseps afectada por las obras de la Línea 9 -anunciada el 30 de diciembre de 2014, tras ha-

\footnotetext{
La línea 9 del Metro de Barcelona está considerada una de las obras públicas más ambiciosas de Europa. Además de dar servicio a barrios que no disponen de metro, deberá unir cinco municipios metropolitanos y equipamientos estratégicos de la ciudad por medio de la línea subterránea más larga del continente.
} 
ber sido confirmada la suspensión sine die de la construcción de esta infraestructura en un importante tramo de la ciudad que incluía la estación prevista en la plaza- reabrió todavía más la controversia. En los meses previos al anuncio de la licitación de las obras de reurbanización, el Ayuntamiento acordó con la AVC Lesseps una serie de modificacione ${ }^{27}$ que alteraban diferentes aspectos del proyecto consensuado en 2003 y que no se habían podido ejecutar debido a la intromisión de las obras del metro.

Ante la inmediatez de la reurbanización, Amics de Lesseps se apresuró a convocar la mesa redonda "Combates por Lesseps", a fin de denunciar públicamente aquellos acuerdos y buscar un clima favorable a su impugnación. Movilizando para ello a los principales protagonistas "expertos" de la primera etapa de la controversia, fundamentalmente arquitectos, la entidad vecinal pretendía escenificar el aval de algunas figuras clave como respaldo intelectual de su versión de la plaza, claramente alineada con la ejecución del proyecto original. Ahora bien, aquella mesa redonda, que parecía haber sido concebida como una puesta de largo de un nuevo combate, enseguida tomó otro cariz. Nada más comenzar, el portavoz de la asociación convocante anunció que tenía buenas noticias y que, contra todo pronóstico, se había alcanzado un acuerdo de última hora con el Ayuntamiento que conseguía frenar las modificaciones más polémicas que previamente habían pactado el Ayuntamiento y la asociación de vecinos "rival". Aunque el desacuerdo que había motivado aquel encuentro parecía haber desaparecido, la reunión se celebró igualmente, y tanto las personas invitadas a la mesa redonda como muchos de los vecinos asistentes no dudamos en tomar la palabra. Tal y como intenté explicar en mi intervención, bajo mi punto de vista, el conflicto de Lesseps no se resolvería ni mediante un combate entre bandos que acabase en una victoria de parte, ni tampoco con pactos diseminados y poco transparentes que incluyesen tan solo a las dos asociaciones vecinales hegemónicas. Al contrario, el reto continuaba siendo el mismo que años atrás: la exploración y composición colectiva de un mundo en común, de cuya dinámica resultase la ampliación y refundación del consenso vecinal. Sería la asunción y efectuación de ese desafío cosmopolítico lo que permitiría traer a la existencia aquella otra plaza Lesseps posible, cuya formalización y reensamblaje, por otra parte, deberían nutrirse de una multiplicidad de versiones que encontrarían a muchos de sus portavoces tan lejos de las filas del Ayuntamiento como de las dos asociaciones vecinales representativas.

Ahora sí, ha llegado la hora de concluir. Con este artículo he pretendido hacer dos cosas: por una parte, sumarme a los espacios de posibilidad y pensamiento propuestos por aquellos autores que, tras alertar del preocupante estancamiento investigador de la geografía urbana, han intentado renovar su repertorio conceptual -sobre todo el espacio público- y trascender sus límites epistemológicos para poder entenderse mejor con los retos y la complejidad de la ciudad contemporánea. Por otra parte, he querido dar cuenta de una controvertida transformación urbanística, estudiándola esta vez no como un conflicto con una distribución de los posibles dada de antemano, sino como un proceso de traducción que, a la postre, acabaría evidenciando un problema de representación con implicaciones mucho más enjundiosas para los estudios de la ciudad, el diseño urbano y las políticas públicas. Me refiero, entre otras cosas, al agotamiento de

\footnotetext{
Entre las alteraciones acordadas cabe destacar: una nueva ubicación para el área de juegos infantiles que el proyecto original había situado en la zona afectada por las obras del metro; la desaparición o resituación de una fuente ornamental que habían exigido los vecinos en el transcurso del proceso participativo; la irrupción de un área de recreo de perros, exigida por la AVC Lesseps como medida de gestión ante la presencia de animales domésticos en la zona de césped; o el sellado del lucernario con el que el autor del proyecto pretendía señalar simbólicamente la relación de la superficie de la plaza con su subsuelo.
} 
una manera de gobernar la ciudad según una lógica representativa, tecnocrática y jerárquica, claramente desbordada por un deseo común de más y mejor democracia. Ahora bien, lejos de operar como compartimentos estancos, tanto el análisis de los acuerdos y desacuerdos de la remodelación de Lesseps como la emergencia de nuevas perspectivas críticas para la geografía urbana se encuentran fuertemente entrelazadas. El desborde democratizador identificado en la controversia no solo echa por tierra la organización bicameral de la ontología moderna, la lógica de la doble delegación o el mito de la neutralidad de los expertos; también pone en evidencia los límites de la conceptualización del espacio público como una representación unívoca. Es aquí donde entra en juego el concepto de los ensamblajes urbanos. Gracias a su énfasis en la relacionalidad, la multiplicidad, la materialidad, lo virtual o las capacidades emergentes de las entidades que componen lo urbano, los ensamblajes -copartícipes del programa teórico y del nuevo estilo investigador propuesto por la ANT y la NRT- proporcionan dos importantes orientaciones para el diseño de los espacios públicos y su revitalización como objeto de estudio. Por una parte, facilitan la descajanegrización, esa operación que permite visibilizar y politizar mediaciones, relaciones y entidades habitualmente escamoteadas al control ciudadano y excluídas del interés investigador; y, por otra parte, invitan a la articulación alternativa y democratizadora de dichas mediaciones: la posibilidad del reensamblaje del espacio público en términos de igualdad y justicia. Sin duda, los ensamblajes parecen un buen aliado para deshacerse de las limitaciones impuestas por aquellas geografías muertas que, debido a su dependencia de alguna prioridad estructural, cerraban la puerta de antemano a otras indagaciones y articulaciones posibles del espacio público, esto es, a que las cosas en la ciudad puedan ser pensadas y compuestas de otra manera.

\section{Referencias bibliográficas}

ANDERSON, B. \& McFARLANE, C. Assemblage and geography. Area, 2011, Vol. 43, № 2, p. 124-127.

BORJA, J. Llums i ombres de l'urbanisme de Barcelona. Barcelona: Empúries, 2010.

BUSER, M. Thinking thorugh non-representational and affective atmospheres in planning theory and practice. Planning Theory, 2014, Vol. 13, No 3, p. 227-243.

CADMAN, L. Nonrepresentational Theory/Nonrepresentational Geographies. In: KITCHIN, R. \& THRIFT, N. (editors). International Encyclopaedia of Human Geography, 7. Amsterdam: Elsevier, 2009, p. 456-63.

CALLON, M. Algunos elementos para una sociología de la traducción: la domesticación de las vieiras y los pescadores de la bahía de St. Brieuc. En: IRANZO, J.M. y BLANCO, J.R. (editores). Sociología de la ciencia y la tecnología. Madrid: CSIC, 1995, p. 259-282.

CALLON, M. El proceso de construcción de la sociedad. El estudio de la tecnología como herramienta para el análisis sociológico. En: DOMĖNECH, M. y TIRADO, F.J. (editores). Sociología simétrica. Ensayos sobre ciencia, tecnología y sociedad. Barcelona: Gedisa, 1998, p. 143-170.

CALLON, M.; LASCOUMES, P. \& BARTHE, Y. Acting in an uncertain world: An essay on technical democracy. Cambridge, MA \& London: MIT Press, 2009. 
CALLON, M. \& LATOUR, B. Unscrewing the big Leviathan: How actors macro-structure relaity and how sociologists help them to do so. In: KNORR-CETINA, K. \& CICOUREL, A. (editors). Advances in social theory and methodology. London: Routledge \& Kegan Paul, 1981, p. 277-303.

CHINCHILLA, I. y MUNIESA, F. La controversia como herramienta proyectual. En: HERNÁNDEZ AJA, A. (editor). La Sostenibilidad en el Proyecto Arquitectónico y Urbanístico, Madrid: IAU+S, 2004, p. 278281.

COLLS, R. Feminism, bodily difference and non-representational geographies. Transactions of the Institute of British Geographers, 2012, Vol. 37, No 3, p. 430-445.

DELEUZE, G. El Bergsonismo. Madrid: Cátedra, 1987.

DELEUZE, G. Crítica y clínica. Barcelona: Anagrama, 1996.

DELEUZE, G. Diferencia y repetición. Buenos Aires: Amorrortu, 2002.

DELEUZE, G. En medio de Spinoza. Buenos Aires: Cactus, 2008.

DELEUZE, G. y GUATTARI, F. Kafka: por una literatura menor. México D.F.: Era, 1978.

DOMĖNECH, M. y TIRADO, F. J. (editores). Sociología simétrica. Ensayos sobre ciencia, tecnología y sociedad. Barcelona: Gedisa, 1998.

DOMĖNECH, M. y TIRADO, F. J. Ciencia, tecnología y ciudadanía: La cosmopolítica y la reinvención de la democracia. En: GONZÁLEZ, M.T. y LÓPEZ, A. (editores). Innovación, conocimiento científico y cambio social ensayos de sociología ibérica de la ciencia y la tecnología. Madrid: Centro de Investigaciones Sociológicas, 2011, p. 37-52.

DOMíngueZ RUBIO, F. \& FOGUÉ, U. Technifying Public Space and Publicizing Infrastructures: Exploring New Urban Political Ecologies through the Square of General Vara del Rey. International Journal of Urban and Regional Research, 2013, Vol. 37, No 3, p. 1035-1052.

ESTÉVEZ, B. La idea de espacio público en geografía humana. Hacia una conceptualización (crítica) contemporánea. Documents d'Anàlisi Geogràfica, 2012, Vol. 58, No 1, p. 137-163.

ESTÉVEZ, B. La controvèrsia de la Plaça de Lesseps (Barcelona). Una oportunitat per a repensar la condició dels espais públics urbans. Barcelona: Universitat Autònoma de Barcelona, Departament de Geografia, 2014.

Disponible en Internet: http://hdl.handle.net/10803/283531.

FARÍAS, I. Introduction: decentering the object or urban studies. In: FARÍAS, I. \& BENDER T. (editors). Urban assemblages. How Actor-Network Theory changes urban studies. London: Routledge, 2010, p.1-24.

FARÍAS, I. Ensamblajes urbanos: la TAR y el examen de la ciudad. Athenea digital. 2011a, Vol. 11, No 1, p. 15-40. Disponible en Internet: http://www.raco.cat/index.php/Athenea/article/view/244663. 
FARÍAS, I. The politics of urban assemblages. City, 2011b, Vol. 15, No 3-4, p. 365-374.

FOUCAULT, M. El filósofo enmascarado. En: FOUCAULT, M. Estética, ética y hermenéutica, Barcelona: Paidós, 1999, p. 217-224.

GIL-FOURNIER, M. El arquitecto como cuidador urbano. La ciudad viva. 2012. Disponible en Internet: http://www.laciudadviva.org/blogs/?p=13071.

GONZÁLEZ, I. Ciudad y alquimia en Lesseps. La Vanguardia (Culturas), 20 de agosto de 2003, p. 16-17.

GONZÁLEZ, I. Nous criteris per a la reforma de la plaça Lesseps: Memòria, documentació $i$ conclusions obtingudes a partir del procés participatiu dut a terme els dies 9, 10 i 11 de setembre 2002 (inédito).

GRAÑA, F. ¿Democratizar la democracia? Las nuevas formas de diálogo social. Boletín técnico interamericano de formación profesional. Diálogo social, 2005, No 156, p. 125-148.

HABER, A. Nometodología Payanesa: Notas de metodología indisciplinada (con comentarios de Henry Tantalean, Francisco Gil García y Dante Angelo). Revista Chilena de Antropología, 2011, № 23, Disponible en Internet: http://www.revistas.uchile.cl/index.php/RCA/article/view/15564/16031.

HEYNEN, N.; KAIKA, M. \& SWYNGEDOUW, E. (editors). In the nature of cities: Urban political ecology and the politics of urban metabolism. Londres: Routledge, 2006.

INGOLD, T. That's enough about ethnography! Hau: Journal of Ethnographic Theory, 2014, Vol. 4, No 1, p. 283-395.

$\mathrm{KOCH}$, R. \& LATHAM, A. Rethinking urban public space: accounts from a junction in West London. Transactions of the Institute of British Geographers, 2012, Vol. 37, № 4, p. 515-529.

LATHAM, A. Research, performance, and doing human geography: Reflections on the diary photograph. Environment and Planning A, 2003, Vol. 35, No 11, p. 1993-2017.

LATHAM, A. \& CONRADSON, D. The possibilities of performance. Environment and Planning A, 2003, Vol. 35, No 11, p. 1901-1906.

LATOUR, B. Ciencia en acción. Cómo seguir a los científicos e ingenieros a través de la sociedad. Barcelona: Labor, 1992.

LATOUR, B. When things strike back: a possible contribution of science studies to the social sciences. British Journal of Sociology, 2000, Vol. 51, No 1, p. 107-123.

LATOUR, B. La esperanza de Pandora. Ensayos sobre la realidad de los estudios de la ciencia. Barcelona: Gedisa, 2001. 
LATOUR, B. De las 'cuestiones de hecho' a los 'estados de cuestiones'. ¿Qué protocolos tenemos para los nuevos experimentos colectivos". En: LUQUE, E. y GÓMEZ, C. (editores). Medio ambiente y sociedad. Madrid: UNED, 2004a, p. 117-137.

LATOUR, B. Why has critique ran out of steam? From matters of facto to matters of concern. Critical Inquiry, 2004b, Vol. 30, No 2, p. 225-248.

LATOUR, B. Nunca fuimos modernos. Ensayo de antropología simétrica. Buenos Aires: Siglo XXI, 2007a.

LATOUR, B. Turning around politics: A note on Gerard de Vries' Paper. Social Studies of Science, 2007b, Vol. 37, No 5, p. 811-820.

LATOUR, B. Reensamblar lo social. Una introducción a la teoría del actor-red. Buenos Aires: Manantial, 2008.

LATOUR, B. \& WOOLGAR, S. La vie de laboratoire. La production des fets scientifiques, Paris: La Découverte, 1979.

LAW, J. Technology and heterogeneous engineering: the case of the Portuguese expansion. In: BIJKER, W.; HUGUES, T.P. \& PINVH, T.J. (editors). The social construction of Technical Systems: new directions in the sociology and history of technology. Cambridge: MIT Press, 1987, p. 111-134.

LAW, J. After ANT: complexing, naming and topology. In: LAW, J. \& HASSARD, J (editors). Actor Network Theory and After. Oxford: Blackwell, 1999.

LAW, J. Actor Network Theory and Material Semiotics. In: TURNER, B. (editors). The New Blackwell Companion to Social Theory. Oxford: Wiley-Blackwell, 2008, p.141-158.

LAW, J. \& HASSARD, J. (editors). Actor Network Theory and After. Oxford: Blackwell, 1999.

LAW, J y MOL, A. Notas sobre el materialismo. Política y sociedad, 1993/1994, Vol. 14/15, p. 47-57.

LEES, L. Towards a Critical Geography of Architecture: the case of an ersatz colosseum. Ecumene: A Journal of Cultural Geographies, 2001, Vol. 8, № 1, p. 51-86.

LEES, L. Urban Geography: 'New' urban geography and the ethnographic void. Progress in Human Geography, 2003, Vol. 27, No 1, p. 107-113.

LÓPEZ, D. Transiciones hacia otra(s) teoría(s) del actor-red: agnosticismo, interés y cuidado. En: TIRADO, F. y LÓPEZ, D. (editores). Teoría del actor-red. Más allá de los estudios de ciencia y tecnología. Barcelona: Amentia, 2012, p. 157-186.

LORIMER, H. Cultural geography: the busyness of being 'more-than-representational'. Progress in Human Geography, 2005 Vol. 29, № 1, p. 83-94. 
LORIMER, H. Cultural geography: worldly shapes, differently arranged. Progress in Human Geography, 2007, Vol. 31, No 1, p. 89-100.

LORIMER, H. Cultural geography: nonrepresentational conditions and concerns. Progress in Human Geography, 2008, Vol. 32, N4, p. 551-559.

MARRERO, I. Por una teoría del actor-red menor: Perspectivismo y monadología. En: TIRADO, F. y LÓPEZ, D. (editores). Teoría del actor-red. Más allá de los estudios de ciencia y tecnología. Barcelona: Amentia, 2012, p. 331-355.

MASSUMI, B. Parables for the virtual: Movement, Affect, Sensation. Durham: Duke University Press, 2002.

McFARLANE, C. Assemblage and Critical Urban Praxis: Part One: Assemblage and critical urbanism. City, 2011a, Vol. 15, № 2, p. 204-224.

McFARLANE, C. The city as assemblage: dwelling and urban space. Environment and Planning D: Society and Space, 2011b, Vol. 29, 649-671.

MOL, A. The body multiple: Ontology in medical practice. Durham: Duke University Press, 2002.

MUÑOZ, F. UrBANALización. Paisajes comunes, lugares globales. Barcelona: Gustavo Gili, 2008.

RODRÍGUEZ-GIRALT, I.; ROJAS, D. y FARÍAS, I. Cosmopolíticas. Revista Pléyade, 2014, Vol. 14, p. $1-15$.

SANFELIU, C. Projecte de reforma de la plaça Lesseps. INDE: informació i debat, 2003, p. 28-29.

SOLÀ-MORALES, M. Centralitat simulada, centralitat dissimulada. Quaderns d'arquitectura i urbanisme, 2006, Vol. 249, p. 56-59.

STENGERS, I. Including nonhumans in political theory: Opening pandora's box? In: BRAUN, B. \& WHATMORE, S. (editors). Political matter: Technoscience, democracy, and public life. Minneapolis: University of Minnesota Press, 2010, p. 3-33

THRIFT, N. Spatial formations. London: Sage, 1996.

THRIFT, N. The still point. In: PILE, S. \& KEITH, M. (editors). Geographies of resistance. London: Routledge, 1997, p. 124-151.

THRIFT, N. Performance and... . Environment and Planning A, 2003, Vol. 35, № 11, p. 2019-2024.

THRIFT, N. Summoning life. In: CLOKE, P; GOODWIN, M \& CRANG, P. (editors). Envisioning Human Geographies. London: Arnold, 2004, p. 81-103.

THRIFT, N. Non-Representational Theory: Space, Poltics, Affect. London: Routledge, 2007. 
THRIFT, N \& DEWSBURY, J. Dead geographies and how to make them live. Environment and Planning D: Society and Space, 2000, Vol. 18, No 4, p. 411-432.

VIVEIROS DE CASTRO, E. Metafísicas caníbales. Líneas de antropología postestructural. Buenos Aires: Katz, 2010.

WHATMORE, S. Materialist returns: practicing cultural geography in and for a more-than-human world. Cultural Geographies, 2006, Vol. 13, No 4, p. 600-609. 
